AperTO - Archivio Istituzionale Open Access dell'Università di Torino

New Insights on the Dynamic Role of the Protecting Agent on the Reactivity of Supported Gold Nanoparticles

This is a pre print version of the following article:

Original Citation:

Availability:

This version is available http://hdl.handle.net/2318/1739978

since 2020-05-27T17:31:45Z

Published version:

DOI:10.1002/cctc.201902061

Terms of use:

Open Access

Anyone can freely access the full text of works made available as "Open Access". Works made available under a Creative Commons license can be used according to the terms and conditions of said license. Use of all other works requires consent of the right holder (author or publisher) if not exempted from copyright protection by the applicable law. 


\title{
New insights on the dynamic role of the protecting agent on the reactivity of supported gold nanoparticles
}

\author{
Giorgio Grillo, ${ }^{a}$ Federica Menegazzo, ${ }^{b}$ Silvia Tabasso, ${ }^{c}$ Michela Signoretto, ${ }^{b}$ Maela Manzoli*a and Giancarlo \\ Cravotto $^{\text {a }}$
}

[a] Dr. G. Grillo, Dr. M. Manzoli, Prof. G. Cravotto, Department of Drug Science and Technology and NIS - Centre for Nanostructured Interfaces and Surfaces, University of Turin, Via Pietro Giuria 9, 10125, Turin, Italy

E-mail: maela.manzoli@unito.it

[b] Dr. S. Tabasso, Department of Chemistry, University of Turin, Via Pietro Giuria 7, 10125, Turin, Italy

[c] Dr. F. Menegazzo, Prof. M. Signoretto, CATMAT Lab, Department of Molecular Sciences and Nanosystems, Ca' Foscari University Venice and INSTM Consortium RU Ve, Via Torino 155, 30170 Venezia Mestre, Italy

\begin{abstract}
A very efficient catalyst (AuCePVA) was prepared by depositing gold colloids on $\mathrm{CeO}_{2}$ and using polyvinyl alcohol (PVA) as protective agent. Complete conversion and selectivity in furfural (2-FA) oxidative esterification to methyl-2-furoate (Me-2-F)was obtained without base under conventional heating at 120 ${ }^{\circ} \mathrm{C}$. AuCePVA was compared with $\mathrm{Au} / \mathrm{CeO}_{2}$ obtained by deposition-precipitation method, pointing out that along with the size of the Au nanoparticles and the surface sites of the ceria support, also PVA chains played a role during reaction. In situ FTIR spectroscopy measurements of adsorbed molecules at controlled temperature and pressure demonstrated that PVA acted not merely as gold stabilizer, but also as mediator during the 2-FA oxidative esterification, leaving both $\mathrm{Au}$ and ceria sites available for catalysis at the reaction temperature. In a perspective of process intensification, the microwave-assisted (MW-assisted) 2-FA oxidative esterification was carried out. Depending on the reaction time and temperature, AuCePVA favoured the oxidation of the hemiacetal into the ester rather than the re-oxidation of the acetal into the ester, due to the formation of $\mathrm{Ce}^{3+}$ sites under MW irradiation.
\end{abstract}

Keywords: $\mathrm{Au} / \mathrm{CeO}_{2} \bullet$ gold catalyst • sol-immobilization • furfural esterification • polyvinylalcohol protecting agent 


\section{Introduction}

In the forthcoming concept of bio-refinery, biomass exploitation into value-added chemicals has been extensively targeted to overcome petrochemical-based processes. The biomass transformation in building blocks has enormous potential production in a wide range of applications. Among these compounds, furfural (2-FA, coming from the hemicellulose C5 fraction of biomass) is currently one of the few which is completely obtained from renewable resources ${ }^{[1]}$.

Indeed, 2-FA is an extremely versatile platform molecule for chemical synthesis, and its derivatives have been proposed for sustainable production of $\mathrm{C} 4$ and $\mathrm{C} 5$ chemicals ${ }^{[2]}$ or for the production of monomers to obtain biopolymers or fuels ${ }^{[3,4]}$. The 2-FA oxidative esterification to Me-2-F is among the large variety of reactions aimed to upgrade lignocellulosic biomass wastes into higher added-value chemicals.

As a matter of fact, alkyl furoates find applications as taste and fragrance component in the fine chemical industry, with a market value around 50-100 US\$/Kg, two orders of magnitude higher than the value of the starting biomass. Transition-metal or organo-homogeneous catalysts are currently used in oxidative esterification $^{[5,6]}$. However, in view of process intensification, cost reduction and low environmental impact, heterogeneous catalysts would be the most advisable choice. Supported gold nanoparticles have proved to be extremely active in 2-FA esterification (Scheme 1), under mild conditions by employing $\mathrm{O}_{2}$ as benign oxidant and even without the use of a base $\left(\mathrm{CH}_{3} \mathrm{ONa}\right.$ or $\left.\mathrm{K}_{2} \mathrm{CO}_{3}\right)$ to enhance the catalysis ${ }^{[7-10]}$ therefore making the process sustainable from both environmental and economic points of view ${ }^{[11]}$.

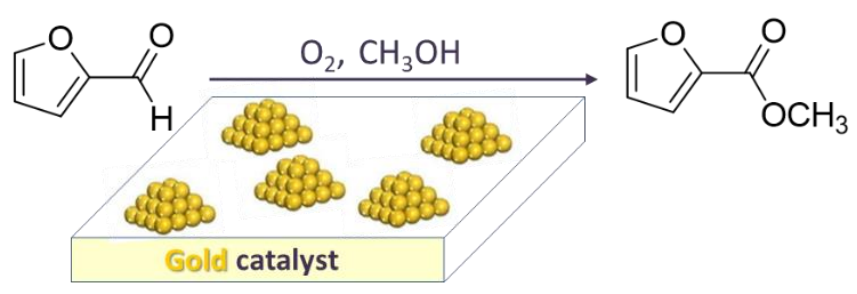

Scheme 1. 2-FA oxidative esterification to Me-2-F.

The strong dependence of the activity on the $\mathrm{Au}$ size, firstly described on $\mathrm{Au} / \mathrm{ZrO}_{2}$, was attributed to the presence of $\mathrm{Au}$ clusters supported on zirconia that dissociate $\mathrm{O}_{2}$ and produce atomic $\mathrm{O}$ able to activate $\mathrm{CH}_{3} \mathrm{OH}^{[7,12]}$. However, it was also found that, when gold is supported on $\mathrm{CeO}_{2}$, the larger is the gold size the higher is the activity in 2-FA esterification, whereas no influence on the selectivity to Me-2-F has been observed under the same experimental conditions ${ }^{[13]}$. The enhanced activity was explained by the presence of lower amounts of carbonate species and more coordinated $\mathrm{Ce}^{4+}$ sites at the surface of the most active catalyst calcined at $500{ }^{\circ} \mathrm{C}$ compared to that calcined at $300{ }^{\circ} \mathrm{C}$. Indeed, a clean surface can be directly related to the capability of ceria to provide activated oxygen. Reverse oxygen spill over occurred at the perimeter of the Au nanoparticles, and these gold sites were showed to be involved in the activation of 
methanol. Indeed, the activity of gold catalysts supported on $\mathrm{CeO}_{2}-\mathrm{Al}_{2} \mathrm{O}_{3}$ mixed oxides was attributed to the oxygen storage capacity of the support. ${ }^{[14]}$

More recently, very efficient gold catalysts were prepared by deposition of gold colloids using polyvinyl alcohol as protective agent. ${ }^{[15][16]}$ Unexpectedly, the catalytic performance was superior than that of $\mathrm{Au} / \mathrm{ZrO}_{2}$ and above all of $\mathrm{Au} / \mathrm{CeO}_{2}$ catalysts prepared by conventional deposition-precipitation method ${ }^{[8,13]}$. This pointed out that along with the size of the gold nanoparticles and the surface sites of the ceria support, also the PVA constituting the Au colloid played a role during 2-FA oxidative esterification. Therefore, in order to investigate the influence of the protecting agent during catalysis, two gold catalysts supported on the same ceria were prepared by sol-immobilisation (AuCePVA) and deposition-precipitation (AuCeDP). The fresh (as synthesised) and used (after catalysis) materials were characterised by Temperature Programmed Oxidation (TPO), high resolution transmission electron microscopy (HR-TEM), diffuse reflectance UV-Vis spectroscopy, and X-Ray Diffraction (XRD). Moreover, detailed in situ Fourier transform Infrared spectroscopy measurements of adsorbed molecules at controlled temperature and pressure were performed to have precise information on the exposed sites and on the effect of the presence of polyvinyl alcohol on these sites. It was previously demonstrated that sol-immobilized catalysts do not require any preliminary activation for at least 6 catalytic runs and can be recovered by simple filtration $^{[15]}$. In order to further optimise the reaction conditions, the 2-FA oxidative esterification was carried out under microwave irradiation in the presence of AuCePVA, AuCeDP and bare ceria catalysts.

\section{Results and Discussion}

\section{Preliminary characterization and catalytic activity}

HR-TEM analyses were carried out on AuCePVA and AuCeDP as synthesised catalysts and the results are summarised in Figure 1. Firstly, both catalysts are supported on the (111), (200) and (220) faces of cubic $\mathrm{CeO}_{2}$ (JCPDS file number 34-394). In addition, the (200) face of $\mathrm{Ce}_{6} \mathrm{O}_{11}$ monoclinic phase (JCPDS file number 32-196) was also detected in the case of AuCePVA. On this catalyst, Au nanoparticles with average size of $3.0 \pm 1.6 \mathrm{~nm}$ (highlighted by circles in the image reported in Figure 1a) were observed.

It is worth noticing that the particle size distribution obtained for this catalyst indicates that the large majority of the nanoparticles have size between 2.5 and $3 \mathrm{~nm}$. Conversely, almost $50 \%$ of the Au species detected on AuCeDP has $1 \mathrm{~nm}$ size (Figure 1b). On this catalyst the gold particles (the EDS spectrum of the Au nanoparticle shown in Figure $1 \mathrm{~b}$ is reported in Figure $\mathrm{SI}-2 \mathrm{a}$ ) have an average size of $3.4 \pm 1.4 \mathrm{~nm}$. For further information, some big Au agglomerates with size around $25 \mathrm{~nm}$ have been also observed (Figure SI$2 b)$. These features were corroborated by DR UV-Vis analyses reported in Figure $1 c$ and performed to have information on the electronic properties of the Au nanoparticles of the AuCePVA (orange line) and AuCeDP (red line) catalysts. 

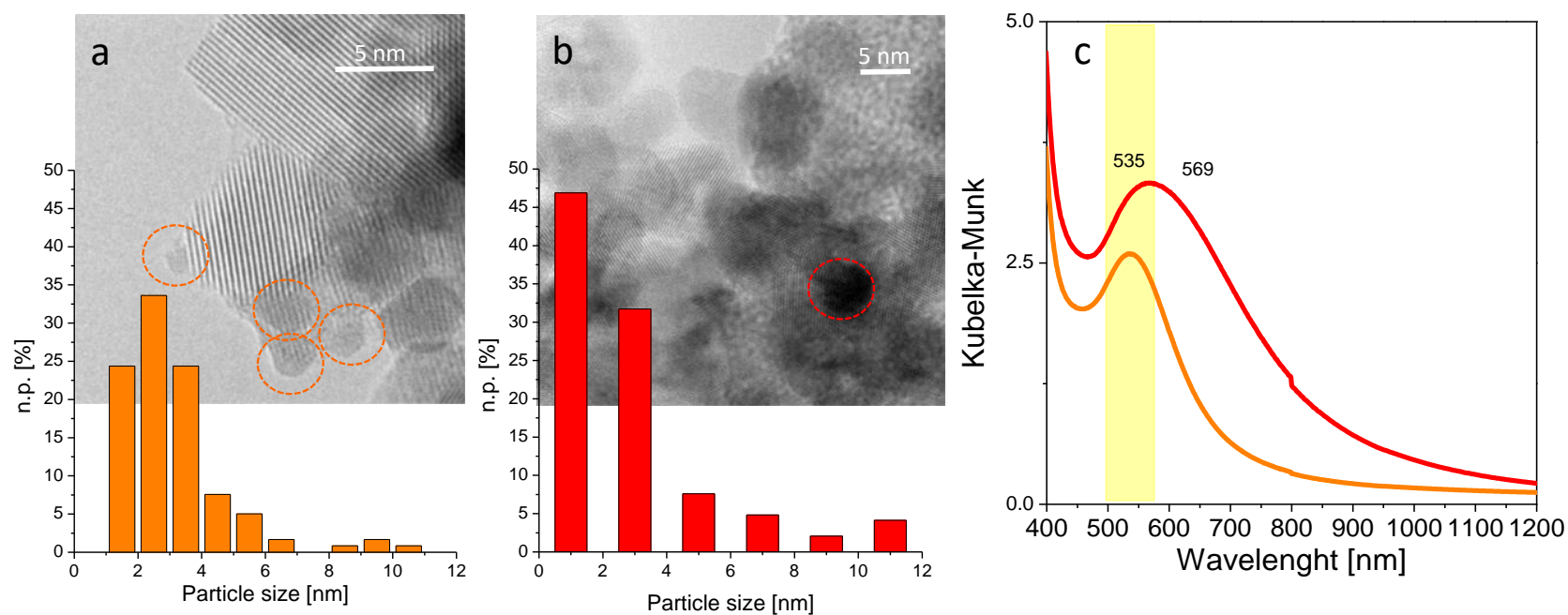

Figure 1. HR-TEM images and Au particle size distributions of the AuCePVA (a) and AuCeDP (b) as synthesised catalysts. Instrumental magnification: $500000 X$, n.p. [\%]= number of counted particles of diameter di. DR UV-Vis spectra (c) collected on AuCePVA (orange line) and AuCeDP (red line) as synthesised catalysts.

A broad absorption with maximum around $570 \mathrm{~nm}$, due to the localized surface plasmon resonance of supported gold nanoparticles ${ }^{[17]}$ was observed in both cases. Both intensity and position of the plasmonic band depend on the nature of the metal that constitutes the nanoparticles and on their size, shape, structure and composition as well as on the dielectric constant of the surrounding medium. ${ }^{[18]}$ However, the plasmonic band of the AuCeDP sample is broader and is higher in intensity than that related to AuCePVA, which indicates that Au nanoparticles ${ }^{[19-21]}$ with heterogeneous size are present. Indeed, in the case of AuCePVA the plasmonic band is narrow and is centred at $535 \mathrm{~nm}$, revealing that Au colloids with homogeneous size were obtained in the presence of the PVA protecting agent.

These spectroscopic features, corroborated by HR-TEM results, point out a beneficial role played by the solimmobilization procedure in efficiently stabilizing the Au nanoparticles against coalescence during synthesis and presumably under reaction conditions ${ }^{[22]}$. Moreover, the presence of PVA on the ceria surface was confirmed by TPO measurements carried out on both catalysts for the sake of comparison (Figure SI-1).

Table 1 contrasts the catalytic results obtained by carrying out the 2-FA oxidative esterification to Me-2-F under previously optimised experimental conditions (conventional heating at $120^{\circ} \mathrm{C}, 90 \mathrm{~min}$ reaction time and in the presence of 6 bar $\left.\mathrm{O}_{2}\right)^{[8,23]}$. AuCePVA gave almost complete conversion $(>99 \%)$ and selectivity (>99\%), whereas $74 \%$ conversion is achieved on AuCeDP.

Interestingly, despite the protecting agent may compete with reactant molecules by interacting with the nanoparticle surface and blocking the active sites ${ }^{[24,25]}$, such catalytic performances were maintained for 6 catalytic runs without requiring any activation procedure, as in the case of AuCeDP (oxidation at $4500^{\circ} \mathrm{C}$ ) ${ }^{[15]}$. Therefore, the presence of PVA plays a role in stabilizing the gold nanoparticles without preventing the 
reaction. Indeed, by looking at the DR UV-Vis spectra shown in Figure 2 and related to as synthesised AuCePVA (orange line) and after 2-FA oxidative esterification to Me-2-F (purple line) only small changes of the gold plasmonic band in terms of both position and shape are detected.

Table 1. Catalytic activity in the 2-FA oxidative esterification to Me-2-F at $120^{\circ} \mathrm{C}$ and in the presence of 6 bar $\mathrm{O}_{2}$.

\begin{tabular}{lll}
\hline Catalyst & Conversion (\%) & Selectivity (\%) \\
\hline AuCeDP & 74 & $>99$ \\
AuCePVA & $>99$ & $>99$ \\
\hline
\end{tabular}

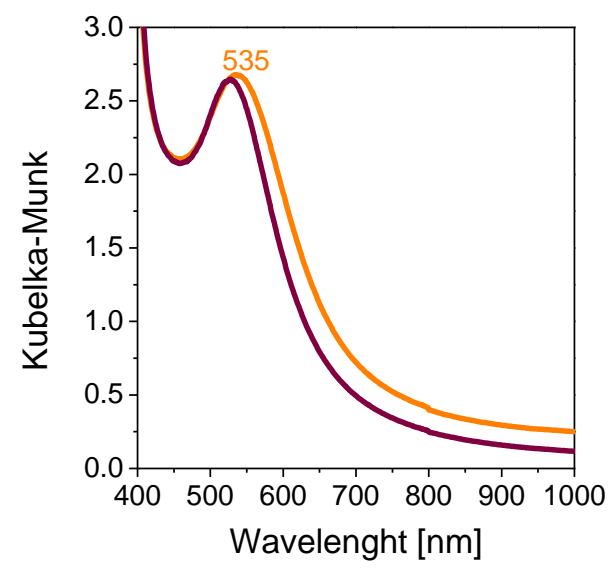

Figure 2. DR UV-Vis spectra collected on the AuCePVA catalyst as synthesized (orange line) and after 2-FA oxidative esterification to Me-2-F (wine line).

This indicates that contained metal coalescence has occurred during reaction, as also validated by an average particle size of $4.6 \pm 1.8 \mathrm{~nm}$ (Figure SI-3).In this frame, the interaction between the gold nanoparticle surface and the PVA protective agent assumes pivotal importance. Indeed, it can be proposed that the milder is such interaction, the higher is the accessibility to reactants ${ }^{[22]}$, resulting in an improved catalytic activity.

\section{Role of the protecting agent}

To shed light on the role of the protecting agent, an extended FTIR characterisation of the AuCePVA catalyst has been carried out in both controlled atmosphere and temperature. Some of the experiments were performed also on AuCeDP to highlight the effect of the presence of PVA on the exposed sites. This approach envisages $\mathrm{CO}$ adsorption at low temperature $\left(-180^{\circ} \mathrm{C}\right)$ to probe the exposed sites of the metal and of the support under different experimental conditions, in order to investigate the behaviour of the PVA protecting agent as well as to mimic the reaction conditions.

The AuCePVA catalyst was submitted to a gentle outgassing procedure at r.t., at $50^{\circ} \mathrm{C}$, and at $120^{\circ} \mathrm{C}$, that is the reaction temperature, before the inlet of the CO probe. In Figure 3 the FTIR absorbance spectra of 
AuCePVA outgassed at r.t (light green line), at $50{ }^{\circ} \mathrm{C}$ (green line) and at $120{ }^{\circ} \mathrm{C}$ (dark green line) for 30 minutes are shown in the $1750-650 \mathrm{~cm}^{-1}$ spectroscopic range.

The spectrum of bare PVA in $\mathrm{KBr}$ (orange line) is also reported for the sake of comparison. In the region between 1700-1000 $\mathrm{cm}^{-1}$, the PVA polymer displays rather defined and intense bands related to the bending modes of the $\mathrm{CH}_{2}\left(1500-1200 \mathrm{~cm}^{-1}\right)$ and $\mathrm{OH}$ groups $\left(1200-1000 \mathrm{~cm}^{-1}\right)$, whose intensity depends on the extent of the intra-chain interaction (a function of the length and of the entangling of the chains).

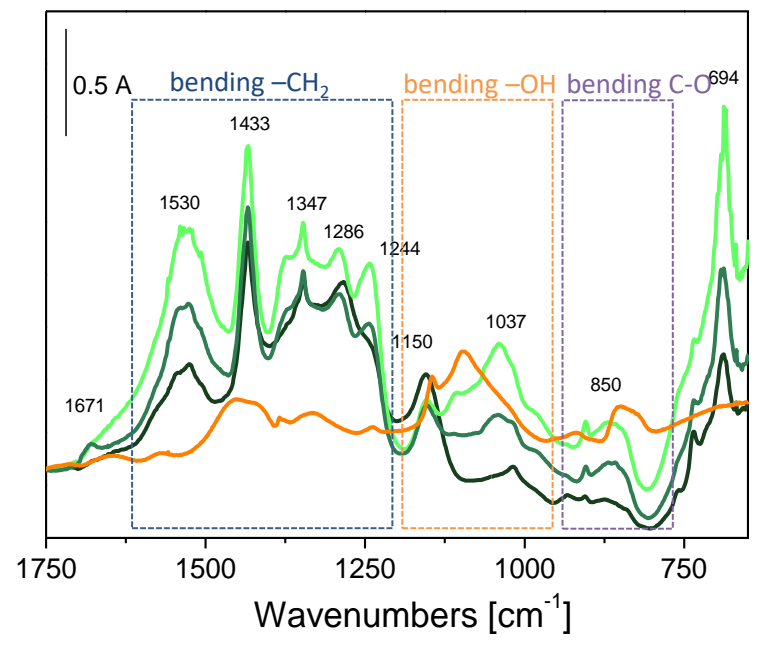

Figure 3. FTIR absorbance spectra of AuCePVA outgassed at r.t (light green line), at $50^{\circ} \mathrm{C}$ (green line) and at $120^{\circ} \mathrm{C}$ (dark green line) for 30 minutes. The spectrum of PVA in $\mathrm{KBr}$ (orange line) is reported for comparison.

In addition, the band at about $850 \mathrm{~cm}^{-1}$ is due to the $\mathrm{C}-\mathrm{O}$ bending mode. When the PVA is used as a protective agent (light green line), the absorptions assigned to the $\mathrm{CH}_{2}$ groups appear more resolved, higher in intensity and shifted towards the high frequencies with respect to the bare polymer (orange line). These features can indicate a decrease of the intra-chain interactions as a consequence of the occurrence of the PVA-metal and PVA-support interactions.

Therefore, the mobility of the chains seems enhanced with respect to those of the bare polymer. Analogously, the $\mathrm{C}-\mathrm{O}$ bending mode is blue shifted in position.

Finally, the bands due to the $\mathrm{OH}$ bending modes are more intense than those of the bare polymer and red shifted, presumably as a result of the interaction between PVA and ceria surface. Except for the $-\mathrm{OH}$ bending region, a small decrease in intensity of the absorption bands took place by increasing the outgassing temperature. At the same time, a decrease in intensity of the band at $1037 \mathrm{~cm}^{-1}$ accompanied by a simultaneous increase of the band at $1150 \mathrm{~cm}^{-1}$ was observed. This behaviour can be an indication that the outgassing induced an increase in mobility of the chains upon water removal.

The FTIR experiments of $\mathrm{CO}$ adsorbed at low temperature were performed at each outgassing step (see Figure SI-4 that shows the whole carboxylic range). 
Upon the inlet of $7.5 \mathrm{mbar} \mathrm{CO}$ at $-180{ }^{\circ} \mathrm{C}$ a band at $2156 / 2157 \mathrm{~cm}^{-1}$ due to $\mathrm{CO}$ adsorbed on $\mathrm{Ce}(\mathrm{IV}) \mathrm{sites}^{[13]}$ was produced on AuCePVA outgassed at room temperature (hereafter denoted as r.t., light green line), 50 ${ }^{\circ} \mathrm{C}$ (green line) and $120{ }^{\circ} \mathrm{C}$ (dark green line). The band blue shifted at $2163 \mathrm{~cm}^{-1}$ when decreasing the CO coverage (black thin lines), and it wore gradually narrower and more intense at increasing temperature, due to the progressive removal of $\mathrm{H}_{2} \mathrm{O}$ (component at about $2150 \mathrm{~cm}^{-1}$ due to $\mathrm{CO}$ in interaction with ceria $\mathrm{OH}$ groups) from the surface of the sample, thus leading to a greater number of support sites available for adsorption.

Figure 4 shows the zoom of the same spectra at low coverages. A weak band at $2125 \mathrm{~cm}^{-1}$, with a shoulder at $2107 \mathrm{~cm}^{-1}$ were observed on AuCePVA outgassed at r.t. for 30 minutes (Figure 4a, light green line). This band decreased progressively in intensity when increasing the outgassing temperature, while the component at $2107 \mathrm{~cm}^{-1}$ due to $\mathrm{CO}$ on $\mathrm{Au}^{0}$ sites ${ }^{[13,26]}$ became more resolved and shifted at $2100 \mathrm{~cm}^{-1}$ (green and dark green lines in Figures $4 \mathrm{~b}$ and $4 \mathrm{c})$. Therefore, the former band can be reasonably assigned to $\mathrm{CO}$ on $\mathrm{Au}^{0}$ sites perturbed by PVA chains (denoted as $\mathrm{Au}^{0}{ }_{\text {PVA }}$ sites in Figure 4).

These results revealed that the presence of PVA affected the nature and accessibility of Au exposed sites following the trend: r.t. $\sim 50{ }^{\circ} \mathrm{C}<120^{\circ} \mathrm{C}$.

Methanol (10 mbar) was adsorbed at r.t. on AuCePVA previously outgassed at $120{ }^{\circ} \mathrm{C}$ to investigate its effect on the nature and abundance of these sites. The same experiment was performed with AuCeDP (Figure SI-5).

Methoxy species adsorbed on top (band at $1104 \mathrm{~cm}^{-1}$ ) and bridged methoxy species (band at about 1040 $\left.\mathrm{cm}^{-1}\right)^{[13,27]}$ were formed on both catalysts even though the bands observed on AuCePVA had lower intensity. In addition, a component at about $1120 \mathrm{~cm}^{-1}$ was observed only in the case of AuCePVA, pointing out the influence of the presence of PVA on the nature and abundance of methoxy species.

The catalysts pre-treated with methanol at r.t. were then outgassed at the same temperature and cooled at $-180^{\circ} \mathrm{C}$ to perform CO adsorption at low temperature. The FTIR difference spectra collected on AuCePVA (a) and AuCeDP (b) previously pre-treated in methanol upon the inlet of $7.5 \mathrm{mbar}$ of $\mathrm{CO}$ at low temperature and subsequent pressure reductions at the same temperature are reported in Figure 5 . In both cases, a band at $2151 \mathrm{~cm}^{-1}$ that blue shifts at decreasing pressure, assigned to $\mathrm{CO}$ adsorbed on $\mathrm{Ce}$ (IV) sites of the support, was observed. Moreover, the shoulder at $2138 \mathrm{~cm}^{-1}$ can be related to liquid like $\mathrm{CO}^{[28]}$ Differently from what observed in the case of AuCeDP (b), no Au sites were detected on AuCePVA (a); neither by increasing the methanol vapour pressure up to 100 mbar nor by directly dropping methanol on the sample pellet before the experiment. At r.t. the PVA chains hindered the Au sites to the CO probe (even if the CO inlet pressure was increased up to 120 mbar) under the adopted experimental conditions (data not shown). ${ }^{[29]} \mathrm{CO}$ was then adsorbed at low temperature on AuCePVA heated at $120^{\circ} \mathrm{C}$, i. e. the reaction temperature, for 30 minutes in the presence of 10 mbar methanol. The FTIR spectra are reported in the carboxylic region in Figure 5c. Two bands at $2142 \mathrm{~cm}^{-1}$ and at $2088 \mathrm{~cm}^{-1}$ were observed. 


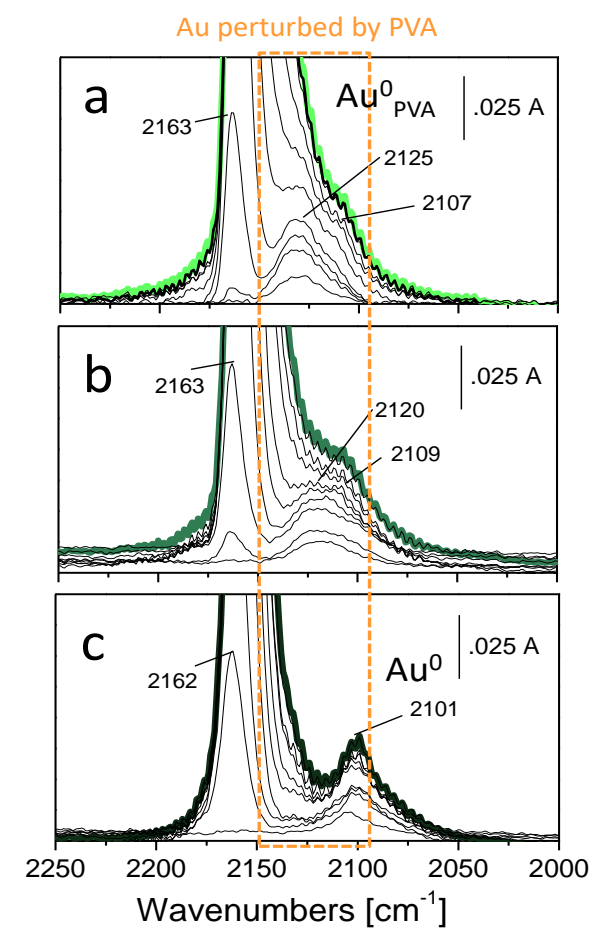

Figure 4. FTIR difference spectra collected upon the inlet of $7.5 \mathrm{mbar} \mathrm{CO}$ at $-180^{\circ} \mathrm{C}$ on AuCePVA outgassed at room temperature (light green line), $50{ }^{\circ} \mathrm{C}$ (green line) and $120^{\circ} \mathrm{C}$ (dark green line) and at reducing CO pressures (light black, lines).
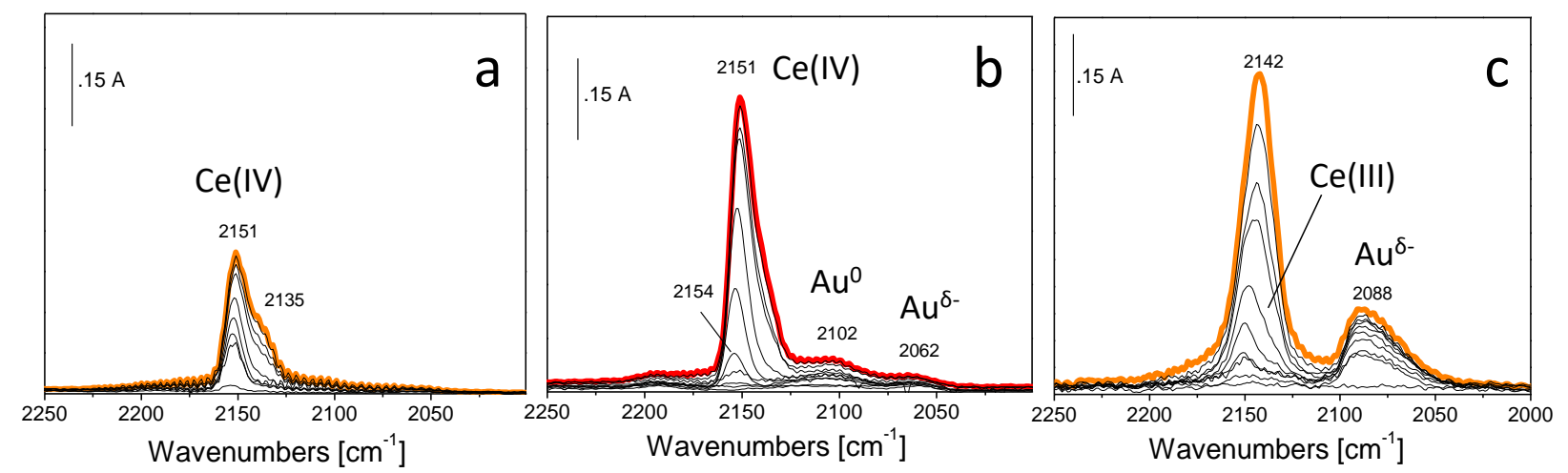

Figure 5. FTIR difference spectra collected on AuCePVA (a), AuCeDP (b) upon the inlet of 7.5 mbar $\mathrm{CO}$ at $-180{ }^{\circ} \mathrm{C}$ on AuCePVA (light green line), $50{ }^{\circ} \mathrm{C}$ (green line) and $120^{\circ} \mathrm{C}$ (dark green line).

The former is quite intense and asymmetric and basing on its behaviour toward the outgassing can be assigned to $\mathrm{CO}$ in interaction with $\mathrm{Ce}(\mathrm{III})$ and $\mathrm{OH}$ groups ${ }^{[13]}$, whereas the latter is due to $\mathrm{CO}$ in interaction with partially negativized $\mathrm{Au}^{\delta-}$ sites. $^{[28]}$ 
Such spectroscopic features indicate that at $120^{\circ} \mathrm{C}$ and in the presence of methanol, the PVA chains are no more able to perform their protective action, making the Au sites accessible to the CO probe. Furthermore, the Au sites are partially negatively charged as a consequence of the reductive effect of methanol at $120^{\circ} \mathrm{C}$ in agreement with the production of Ce(III) sites. Similar results were obtained for AuCeDP (Figure SI-6), but in this case the reductive effect of methanol is more pronounced.

The interaction with 2-FA was also investigated by contacting the AuCePVA catalyst with 10 mbar 2-FA at r.t. before the inlet of $\mathrm{CO}$ at low temperature. No carboxylic bands were observed indicating that the 2-FA molecules adsorbed on the surface of the catalyst and prevented CO adsorption (data not shown). The catalyst was then heated in $2-\mathrm{FA}$ at $120{ }^{\circ} \mathrm{C}$ for 30 minutes and outgassed at r.t., further $\mathrm{CO}$ adsorption at low temperature (Figure SI-7) produced a peak centred at $2138 \mathrm{~cm}^{-1}$, due to physisorbed $\mathrm{CO}^{[28]}$ with a component at $2147 \mathrm{~cm}^{-1}$ related to Ce (IV) sites. ${ }^{[30]}$

Therefore, upon treatment at $120^{\circ} \mathrm{C}$ in the presence of furfural the Au sites were not available to the CO probe. This was not true when furfural is adsorbed at r.t on the AuCePVA catalyst previously submitted to thermal treatment at $120{ }^{\circ} \mathrm{C}$ in the presence of methanol (Figure SI-8). Indeed, beside the same spectroscopic features as for the support sites (peak at $2139 \mathrm{~cm}^{-1}$ with a shoulder at $2147 \mathrm{~cm}^{-1}$ ), the CO probe revealed the presence of a band at $2096 \mathrm{~cm}^{-1}$ due to partially negativized $\mathrm{Au}^{\delta-}$ sites. ${ }^{[28]}$ These results pointed out that the Au sites of the AuCePVA catalyst are available only upon methanol interaction at the reaction temperature.

The interaction with the reaction mixture (methanol:furfural: $\mathrm{O}_{2}-5$ mbar: $10 \mathrm{mbar}: 30 \mathrm{mbar}$ ) at $120{ }^{\circ} \mathrm{C}$ for 30 minutes (Figure SI-9a) produced a large absorption band at $1700 \mathrm{~cm}^{-1}$ (red line) related to the $\mathrm{C}=\mathrm{O}$ stretching mode of the Me-2-F product ${ }^{[8]}$, that can be taken as a spectroscopic indication that the esterification occurred. At the same time, a strong decrease in intensity of the absorption around $1150 \mathrm{~cm}$ 1 , due to methoxy species adsorbed on the support was observed, indicating that methoxy species are directly involved in the furfural esterification reaction. ${ }^{[8]}$ The AuCePVA sample was then outgassed at r.t. and cooled at $-180{ }^{\circ} \mathrm{C}$ to perform CO adsorption (spectra shown in Figure SI-9b). Indeed, Ce (IV) (band at $\left.2154 \mathrm{~cm}^{-1}\right)$ and $\mathrm{Au}^{0}$ sites perturbed by PVA chains $\left(\mathrm{Au}_{\mathrm{PVA}}^{0}\right.$ sites, component at $\left.2135 \mathrm{~cm}^{-1}\right)$ were observed, indicating that the PVA chains allowed the reactants to reach the Au sites.

The same experiment was performed in the absence of oxygen to investigate the effect of the presence of PVA on the oxygen-release capability of ceria during reaction (Figure 6a).

The formation of the broad absorption due to the $\mathrm{C}=\mathrm{O}$ stretching product and, in this case, of the other typical bands of Me-2-F (highlighted by orange boxes) ${ }^{[8]}$, accompanied by a decrease in intensity of the bands related to on top $\left(1115 \mathrm{~cm}^{-1}\right)$ and bridged $\left(1033 \mathrm{~cm}^{-1}\right)$ methoxy species (highlighted by a blue box) were observed. It was previously shown that bridged methoxy species are directly involved in the reaction. ${ }^{\left[{ }^{[8]}\right.}$ 
These spectroscopic findings indicated that the reaction occurred even in the absence of oxygen in the reaction mixture, because ceria provided atomic oxygen under reaction conditions. This is further supported by $\mathrm{CO}$ adsorption after reaction (Figure $6 \mathrm{~b}$ ) that, beside the presence of $\mathrm{Ce}(\mathrm{IV})$ sites, revealed the formation of $\mathrm{Ce}$ (III) (band at $2137 \mathrm{~cm}^{-1}$ ) and of negativized $\mathrm{Au}^{\delta-}$ sites (band at $2084 \mathrm{~cm}^{-1}$ ). ${ }^{[30]}$ Interestingly, the intensity of the band related to the $\mathrm{C}=\mathrm{O}$ stretching mode of the Me-2-F product seemed lower in the presence of oxygen in the reaction mixture, pointing out the pivotal role of the ceria support. The same experiments were performed on the AuCeDP catalyst with similar results (data not shown).

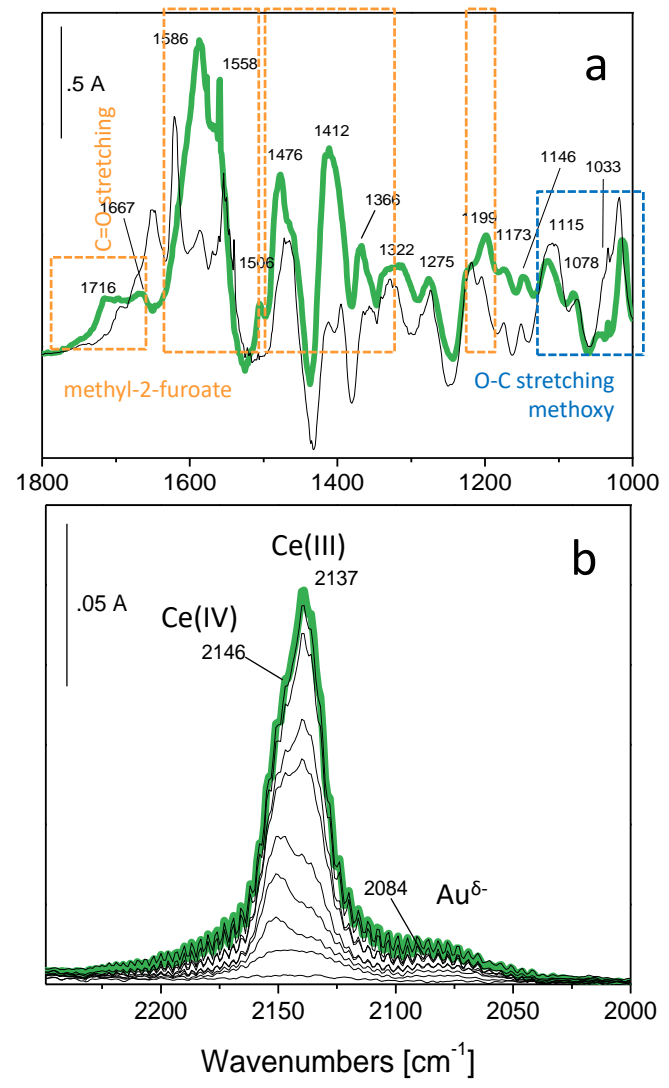

Figure 6. (a) FTIR difference spectra of AuCePVA after the inlet of a methanol:furfural ( 5 mbar: 10 mbar) at room temperature (black line) and at $120{ }^{\circ} \mathrm{C}$ for 30 minutes (green bold line). (b) FTIR difference spectra collected upon the inlet of 7.5 mbar $\mathrm{CO}$ at $-180{ }^{\circ} \mathrm{C}$ on AuCePVA previously heated in a methanol:furfural ( 5 mbar: 10 mbar) mixture at $120^{\circ} \mathrm{C}$ for 30 minutes and outgassed at room temperature (green bold line) and at reducing CO pressures (black lines).

It is worth noticing that the experiments carried out in the absence of oxygen in the reaction mixture revealed that the PVA chains do not compromise the oxygen mobility of the $\mathrm{CeO}_{2}$ support under reaction conditions.

It can be therefore proposed that in reaction conditions the PVA chains, similarly to the branches of a sea anemone, are able to disclose in the reaction mixture allowing the reagents to reach the Au sites which catalyse the reaction (Scheme 1). At r.t., the chains of the PVA protecting agent are closely packed around the gold nanoparticles impeding to both reactants and to the CO probe to reach the Au sites (a). When the 
temperature is increased up to $120^{\circ} \mathrm{C}$ (i.e. the reaction temperature) the mobility of the chains is enhanced and the Au sites became accessible to the reactants.

The spectroscopic results indicated that the PVA chains interact more efficiently with methanol (possibly due to the presence of the - $\mathrm{OH}$ group) than with 2-FA (possibly because it is a less polar molecule than the alcohol).

a

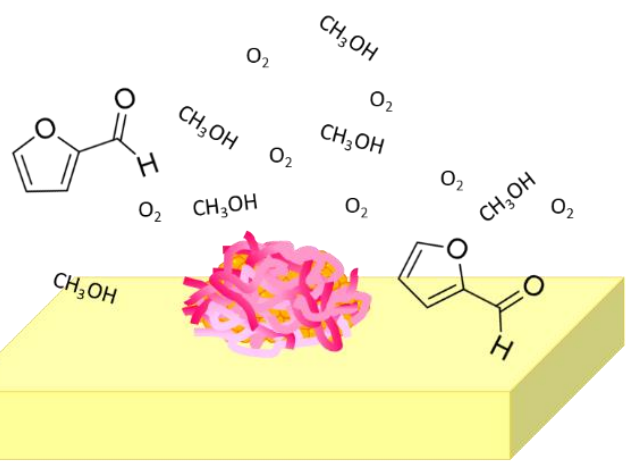

b

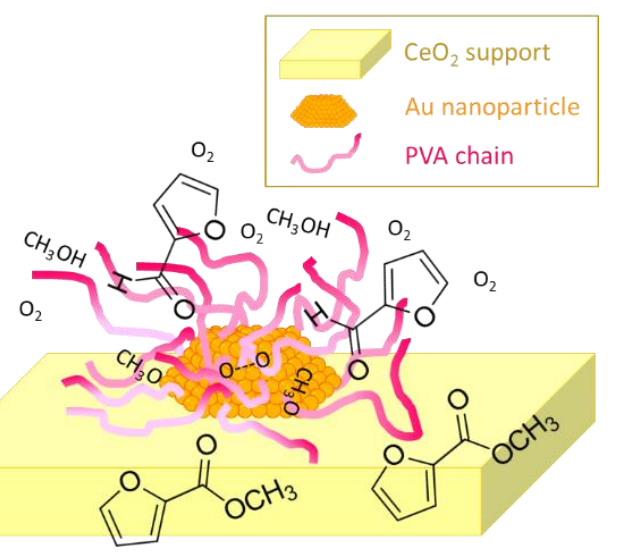

Scheme 1. Behaviour of the PVA protecting agent when contacted with the methanol:furfural:oxygen reaction mixture at room temperature (a) and at $120^{\circ} \mathrm{C}(\mathrm{b})$.

\section{Furfural esterification to Me-2-F under microwave irradiation}

In a perspective of process intensification, the use of a non-conventional enabling technology such as MW, can be strategic to reduce the reaction time. This the consequence of rapid internal dielectric heating, due to the direct interaction among the electromagnetic field and reactants, intermediates, etc. in the reaction medium. ${ }^{[31]}$ The efficiency of $\mathrm{MW}$ is related to thermal effects (involving rapid heating and high bulk reaction temperatures) and other non-thermal effects. The latter are not linked to a macroscopic change in reaction temperature, but involve the production of hot spots at the catalyst surface, resulting in nonequilibrium local heating localized at the metal nanoparticles surface. ${ }^{[32]}$

To investigate the effect of MW on 2-FA oxidative esterification to Me-2-F, preliminary catalytic tests were performed over AuCeDP, AuCePVA as well as bare ceria under similar experimental conditions adopted for the experiments carried out under conventional heating at $120{ }^{\circ} \mathrm{C}$ and 90 minutes, but 12 bar $\mathrm{O}_{2}$. The results of this screening are shown in Figure 7a.

The AuCePVA catalyst gave the best conversion (89.8\%) with respect to AuCeDP (82.2 \%) and bare ceria (74.6\%). No conversion of 2-FA was observed without the catalyst, hence excluding aldehyde autooxidation reactions. However, Me-2-F is not the unique product, as acetal is formed, too. In particular, the selectivity to Me-2-F is much higher on the gold catalysts than on bare ceria (2.0\%) and the selectivity is 
higher in the case of AuCePVA (66.4 \%) than for AuCeDP (53.7 \%). Moreover, the increase in selectivity to Me-2-F corresponds to a decrease in the formation of the acetal. Bare ceria showed almost nihil activity toward the formation of Me-2-F, but differently from conventional heating, reached almost complete selectivity toward the formation of the acetal. The mass balance ranged between $68.8 \%$ and $74.6 \%$, due to the substrate degradation to unidentified compounds (possibly volatile compounds or to humines).

It is worth noting that, differently from what reported in the literature ${ }^{[11,33]}$, the formation of the acetal was never observed under our experimental conditions employing conventional heating ${ }^{[13,23,34]}$, neither in the case of other gold catalysts supported on different oxides. ${ }^{[7,12,16]}$
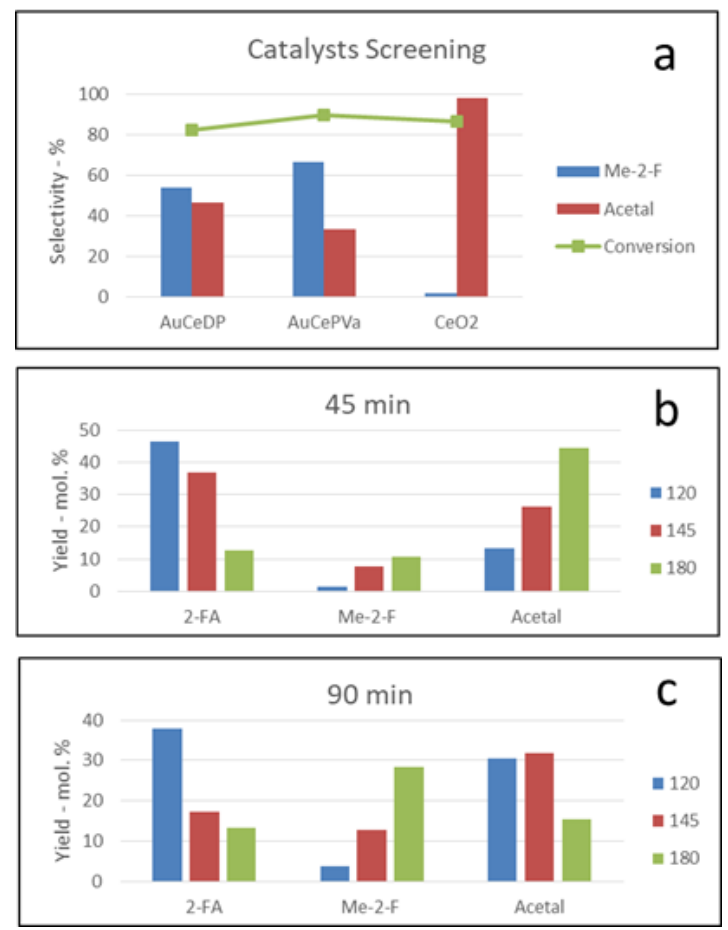

Figure 7. (a) Conversion and selectivity in 2-FA oxidative esterification to Me-2-F at $120{ }^{\circ} \mathrm{C}$ over AuCeDP, AuCePVA and bare ceria. Effect of the temperature after 45 minutes (b) and 90 minutes (c) reaction over AuCePVA in 12 bar $\mathrm{O}_{2}$.

The acetal comes from the addition of methanol to the carbonyl group of the aldehyde to form the $\left(\mathrm{OCH}_{3}\right)_{2}$ acetal group. This reaction takes place if the $\mathrm{C}=\mathrm{O}$ group of 2-FA is activated by Lewis acid sites. ${ }^{[11][33]}$ In order to push the selectivity to Me-2-F over the AuCePVA catalyst, the MW-assisted reaction was performed at different temperature, i.e. 120,145 and $180{ }^{\circ} \mathrm{C}$, given the same $\mathrm{O}_{2}$ pressure (12 bar) and the same reaction time, i.e. 45 minutes (Figure 7b) or 90 minutes (Figure 7c). The heating ramp was the same ( 5 minutes, avg. $875 \mathrm{~W}$ ) for all tests. More in detail, 2-FA is almost unreacted after 45 minutes at $120^{\circ} \mathrm{C}$ and it was necessary to perform the reaction at $180^{\circ} \mathrm{C}$ to appreciate its conversion. The amounts of Me-2- $\mathrm{F}$ and acetal increase with the increase of the reaction temperature, i.e. from $1.4 \mathrm{~mol} . \%$ to $10.7 \mathrm{~mol} . \%$ and from 13.3 mol.\% to 44.5 mol.\%, respectively. However, the percentual molar yield of produced acetal are more than those obtained for Me-2-F at all reaction temperatures. In general, by increasing the reaction 
temperature there was a progressive conversion of furfural, with a parallel increase in acetal formation. This trend was inverted when the reaction time was prolonged to 90 minutes at $180^{\circ} \mathrm{C}$, because a marked increase of Me-2-F (28.4 mol \%) was accompanied by an evident decrease of the amount of acetal (15.4 mol \%). Hence, the effect of the reaction time at $180^{\circ} \mathrm{C}$ was investigated over the AuCePVA catalyst, given the same oxygen pressure (Figure 8a). By increasing the reaction time, an increase of Me-2-F (from 10.7 mol \% up to $38.9 \mathrm{~mol} \%$ ) was observed. At the same time, the amount of acetal diminished from $44.5 \mathrm{~mol} \%$ to $19.7 \mathrm{~mol} \%$. These data can be an indication that 2-FA is firstly converted into the acetal and then the acetal is converted to Me-2-F by increasing the reaction time. This implies that under MW irradiation the conversion of acetal to Me-2-F is slower than acetal formation, which is usually considered the rate limiting step. ${ }^{[33]}$
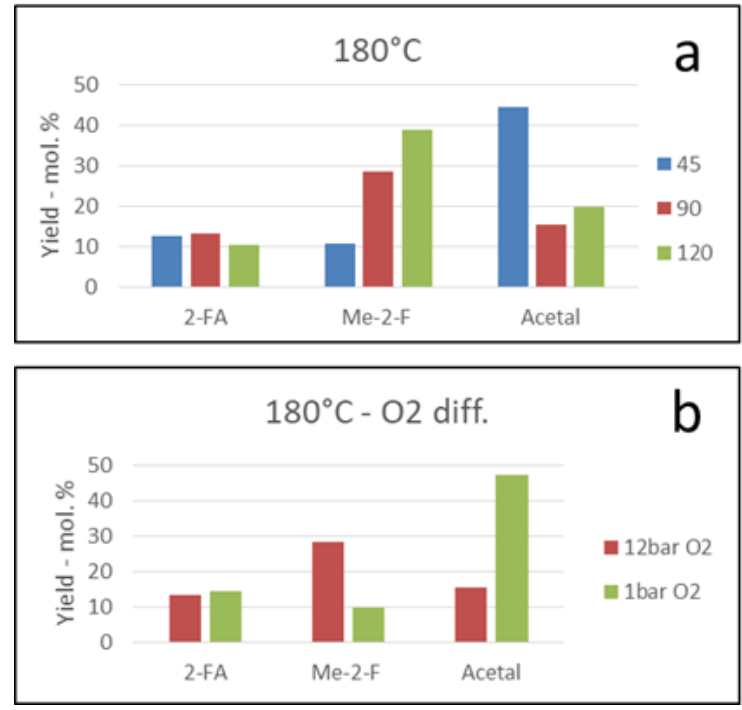

Figure 8. Effect of the reaction time at $180^{\circ} \mathrm{C}$ in 12 bar $\mathrm{O}_{2}$ (a) and effect of the oxygen pressure at $180^{\circ} \mathrm{C}$ for 90 minutes (b)

The effect of oxygen pressure was studied at $180^{\circ} \mathrm{C}$, with a reaction time of 90 minutes (Figure $8 \mathrm{~b}$ ). The acetal formation was favoured when the reaction was carried out in the presence of a lower oxygen pressure ( 1 bar). These results indicated that acetal formation took place under MW irradiation reducing conditions, reasonably in the presence of $\mathrm{Ce}(\mathrm{III})$ Lewis acid sites, as reported previously. ${ }^{[11][33]}$

With the aim to investigate the effect of MW on the AuCePVA catalyst, XRD analyses were carried out on fresh AuCePVA and on the catalyst after different reaction times under $\mathrm{MW}$ irradiation at $120^{\circ} \mathrm{C}$, given the same heating ramp (5 minutes, avg. $875 \mathrm{~W}$ ). The patterns are shown in Figure 9. The peaks related to crystalline ceria in the cubic phase (JCPDS file number 00-001-0800) as well as the main 111 peak at $38.2^{\circ}$ due to crystalline gold in the cubic phase (JCPDS file number 00-001-1172) were observed. Overall, the MW irradiation for increasing times did not significantly affected the crystallinity of the catalyst. The 111 peak of gold did not change by increasing the reaction time under MW irradiation, indicating that the PVA chains can effectively protect the gold nanoparticles under reaction conditions by preventing the metal 
coalescence. However, a more careful inspection of the overlapped patterns put in evidence a gradual decrease in intensity of the 100, 220 and 311 peaks of ceria, possibly accompanied by a small broadening at increasing reaction times (see Figure 9, upward from the left to the right). This trend is more evident in the case of the 100 main peak and can be justified by assuming a decrease in crystallinity along these preferential directions, possibly due to the release of oxygen atoms under the reducing conditions of MW irradiation.
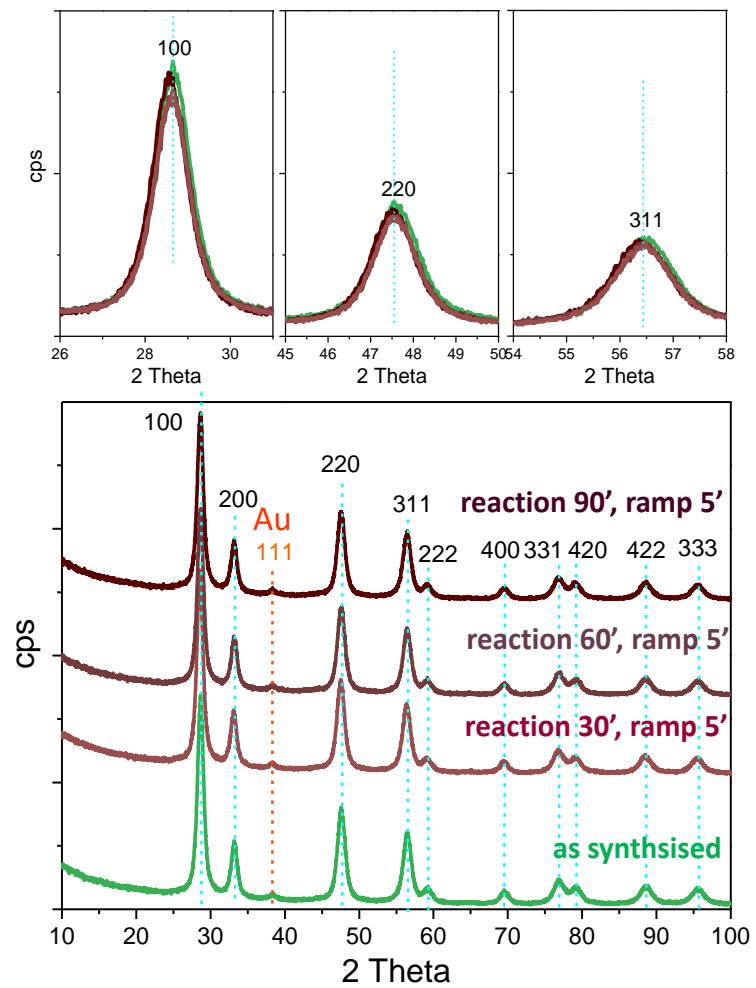

Figure 9. XRD patterns of fresh AuCePVA and of the catalyst after different reaction times under MW irradiation at $120{ }^{\circ} \mathrm{C}$, given the same heating ramp $(5$ minutes). Upward, from the left to the right: zoom of the overlapped patterns on the 100, 220 and 311 peaks of ceria.

Experiments on bare ceria after 30 minutes reaction time under $\mathrm{MW}$ irradiation at $120{ }^{\circ} \mathrm{C}$, at different heating ramps ( 5 minutes, avg. $875 \mathrm{~W}$ and 8 minutes, avg. $522 \mathrm{~W}$ ) revealed analogous behaviour (Figure SI10).

Hence, $\mathrm{MW}$ irradiation had a reducing effect and promoted the formation of $\mathrm{Ce}^{3+}$ acid sites by losing atomic oxygen: indeed acetal production was never observed on these catalysts under conventional heating. Such hypothesis was supported by DR UV-Vis spectroscopy analyses carried out on AuCePVA after MW-Assisted reaction (Figure 10, grey line). The two components at 230 and $265 \mathrm{~nm}$ related to $\mathrm{Ce}^{3+} \leftarrow \mathrm{O}_{2}^{-}$and $\mathrm{Ce}^{4+} \leftarrow \mathrm{O}_{2}^{-}$ charge transfer transitions, respectively ${ }^{[35][36]}$ were accompanied by a well evident red-shift of the electron transition from the valence band to the conduction band $(\mathrm{O}(2 \mathrm{p})$ to Ce (4f) from 332 to $347 \mathrm{~nm}$. Moreover, the absorption edge was found at $422 \mathrm{~nm}$ by means of a tangent analysis, vs. $404 \mathrm{~nm}$ for the sample before and after reaction under conventional heating. It is known that the wavelength of the ceria absorption edge 
is related to the crystallite size ${ }^{[35,37][38]}$. In particular, the smaller is the crystalline size, the lower is the wavelength. Therefore, the MW-assisted loss of atomic oxygen and the simultaneous $\mathrm{Ce}^{3+}$ formation during reaction resulted in a contained decrease of the crystal size of the catalyst, as already indicated by XRD. Combined operando Raman and UV-Vis spectroscopies were employed to perform real-time observations of the dynamic of defects in $\mathrm{Au} / \mathrm{CeO}_{2}$ catalysts under working conditions. ${ }^{[39]}$ It was found that the reduction state of the ceria support strongly affects the catalytic activity. Moreover, oxygen mobility and charge transfer processes induce the reduction at both surface and subsurface of the catalyst. ${ }^{[39-41]}$

Basing on the catalytic tests and the characterization data, it can be proposed that 2-FA esterification to Me-2-F followed two reaction paths. According to Scheme 2, 2-FA can follow Path 1 and be directly converted to the ester by involving the formation of the hemiacetal to Me-2-F.

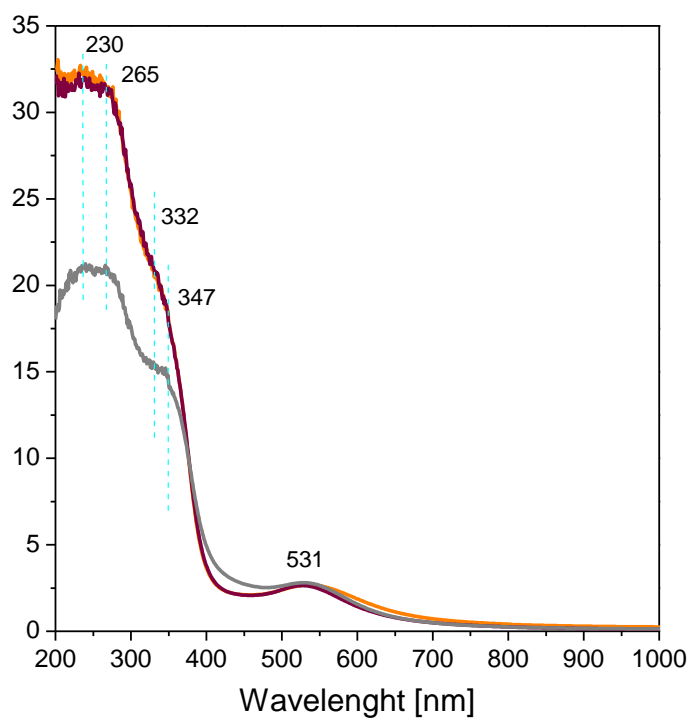

Figure 10. Comparison of the DR UV-Vis spectra collected on the AuCePVA catalyst as synthesized (orange line), after 2-FA oxidative esterification to Me$2-\mathrm{F}$ at $120^{\circ} \mathrm{C}$ for 90 minutes (winee line) and after MW-assisted 2-FA oxidative esterification to Me-2-F at $120^{\circ} \mathrm{C}$ for 90 minutes (grey line).

In this case, the activated $\mathrm{C}=\mathrm{O}$ bond of the aldehyde underwent a nucleophilic attack by methanol and further deprotonation to form the hemiacetal (unstable species, not detected). Alternatively, the reaction proceeded following Path 2 and 2-FA can form the acetal (stable species, detected) that was further converted to Me-2-F. As well known, the reaction involved protonation of the alcoholic group of hemiacetal, dehydration and nucleophilic attack by a second alcohol molecule and deprotonation to form the acetal.

The former mechanism is thermodynamically more favoured owing to the low stability of the hemiacetal. ${ }^{[11]}$ This reaction path was already observed for both AuCeDP and AuCePVA catalysts under conventional heating. ${ }^{[13,23,34]}$ Conversely, the latter one is slower, due to the stability of the acetal, and was proposed previously by Corma et al. ${ }^{[11]}$ 


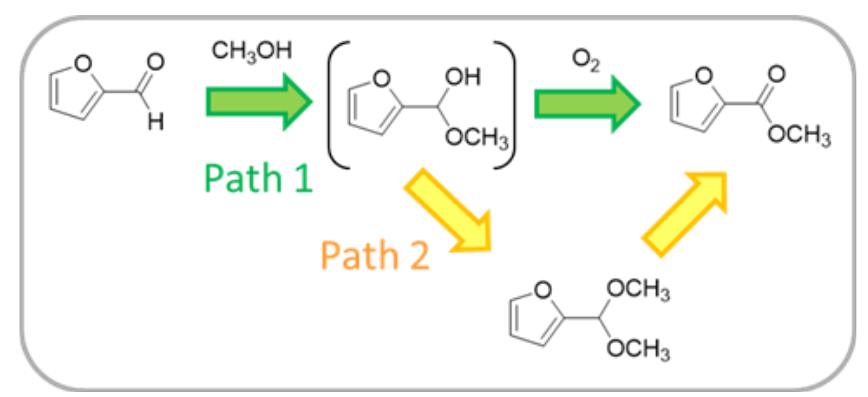

Scheme 2. Proposed reaction paths for the MW-assisted 2-FA esterification to Me-2-F at $120^{\circ} \mathrm{C}$ for 90 minutes in 12 bar oxygen.

In the present study, depending on the reaction time and temperature, the AuCePVA catalyst selectively favoured the reoxidation of the acetal into the ester, due to the formation of $\mathrm{Ce}(\mathrm{III})$ sites under MW irradiation rather than the oxidation of the hemiacetal into the ester.

It is thus reasonable that the acetal was formed preferentially mainly over bare ceria. Conversely, the presence of gold nanoparticles guaranteed efficient methanol activation (forming methoxy species) and possibly facilitated the $\mathrm{H}$ elimination of hemiacetal, as previously hypothesised for Au supported on Ce- $\mathrm{Zr}$ in the oxidative esterification of different benzylic aldehydes. ${ }^{[42]}$

\section{Conclusions}

Gold catalysts supported on ceria $\mathrm{Au} / \mathrm{CeO}_{2}$ were prepared by immobilisation of Au colloids using PVA as protective agent. Such catalysts were proved to be very efficient and stable in 2-FA oxidative esterification to Me-2-F under conventional heating at $120^{\circ} \mathrm{C}$, for 90 minutes and in the presence of 6 bar $\mathrm{O}_{2}$. Indeed, high conversion and complete selectivity to Me-2-F without the presence of a base, improving the sustainability of the process.

Moreover, $\mathrm{O}_{2}$ pressure had not effect on the selectivity and high conversions were achieved even at low pressures.

The comparison with the AuCeDP catalyst revealed the extremely positive effect of the presence of the PVA protecting agent. Particularly the PVA chains (i) controlled the Au size during synthesis, (ii) acted as a mediator in the interaction with reagents, (III) stabilized the Au nanoparticles during reaction (no coalescence). Moreover, isolated $\mathrm{Au}^{0}$ sites perturbed by PVA have been observed.

It has been therefore effectively demonstrated that polyvinyl alcohol molecules acted not merely as gold stabilizer, but also as true mediator during the 2-FA oxidative esterification, leaving both $\mathrm{Au}$ and ceria sites available for catalysis only upon interaction with methanol at $120^{\circ} \mathrm{C}$, i.e. the reaction temperature.

The reaction was carried out also under MW irradiation. It was found that Au nanoparticles were stable under MW-assisted reaction conditions. Moreover, MW promoted the formation of $\mathrm{Ce}^{3+}$ acid sites, which 
gave rise to acetal formation. Two reaction paths have been proposed: Path 1 involved the direct 2-FA conversion to Me-2-F with the hemiacetal species as labile intermediate. This mechanism is thermodynamically favoured and predominates when increasing the temperature. Path 2 encompassed the formation of the stable acetal intermediate that further converted to Me-2-F. This mechanism is slower than Path 1 and is favoured at higher reaction times.

\section{Experimental Section}

\section{Catalyst synthesis}

Two gold catalysts, having a final gold loading of $1.5 \mathrm{wt} \%$ and supported on the same cerium oxide were prepared by (i) sol-immobilisation (AuCePVA) and (ii) deposition-precipitation methods (AuCeDP). Therefore, ceria was firstly synthesized as described elsewhere ${ }^{[23,43,44]}$ and it was submitted to final calcination at $500{ }^{\circ} \mathrm{C}$. As for (i), the preparation has been described previously ${ }^{[23]}$. Briefly, a solution of 1 wt.\% polyvinyl alcohol (PVA) was added to a $\mathrm{HAuCl}_{4}$ aqueous solution under vigorous stirring at $0{ }^{\circ} \mathrm{C}$ in order to obtain a PVA/Au ratio equal to $0.5(\mathrm{w} / \mathrm{w})$. Next a $0.1 \mathrm{M}$ solution of $\mathrm{NaBH}_{4}$ was added, to form a ruby-red metallic sol in which the $\mathrm{NaBH}_{4} / \mathrm{Au}$ ratio was $4(\mathrm{~mol} / \mathrm{mol})$. The sol was promptly immobilized by adding the support under vigorous stirring and aged for 12 hours at $0{ }^{\circ} \mathrm{C}$. The filtered catalyst was washed 5 times with distilled water and dried at $110^{\circ} \mathrm{C}$ for 20 hours. As for (ii), the synthesised ceria was suspended in a $\mathrm{HAuCl}_{4} \cdot 3 \mathrm{H}_{2} \mathrm{O}$ aqueous solution for 3 hours and at $\mathrm{pH}=8.6$ (the $\mathrm{PH}$ was controlled by adding $0,5 \mathrm{M}$ $\mathrm{NaOH}$ ). After filtration the sample was washed 5 times with distilled water, dried at $35{ }^{\circ} \mathrm{C}$ for 20 hours and finally calcined in flowing air $(30 \mathrm{~mL} / \mathrm{min})$ at $500{ }^{\circ} \mathrm{C}$ for 1 hour ${ }^{[13]}$.

\section{Catalyst characterisation}

Temperature programmed oxidation (TPO) measurements were carried out by using a lab made equipment in which $100 \mathrm{mg}$ sample (without any preliminary activation) was heated from $25^{\circ} \mathrm{C}$ to $900{ }^{\circ} \mathrm{C}$ in air (40 $\mathrm{mL} / \mathrm{min}$ ) with $10^{\circ} \mathrm{C} / \mathrm{min}$ temperature rate. The effluent gases were analysed by a Genesys 422 quadrupole mass analyser (QMS). The signals for masses 18, 28, 44, 48, 64 were recorded.

High resolution transmission electron microscopy (HR-TEM) measurements were performed using a side

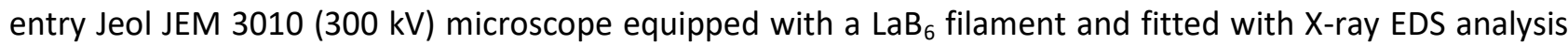
by a Link ISIS 200 detector. Prior to the measure, each sample, in the form of powder, was deposited on a copper grid coated with a porous carbon film. All digital micrographs were acquired by an Ultrascan 1000 camera and the images were processed by Gatan digital micrograph. Histograms of the Au particle size distribution were obtained by considering at least 150 particles on the HR-TEM images, and the mean particle diameter $\left(\mathrm{d}_{\mathrm{m}}\right)$ was calculated as:

$\mathrm{d}_{\mathrm{m}}=\Sigma \mathrm{d}_{\mathrm{i}} \mathrm{n}_{\mathrm{i}} / \Sigma \mathrm{n}_{\mathrm{i}}$ 
where $n_{i}$ is the number of particles of diameter $d_{i}$.

Diffuse Reflectance (DR) UV-Vis analyses were carried out on the samples in the form of powders. The samples were placed in a quartz cell and DR UV-Vis spectra were collected at room temperature (r.t.) on a Varian Cary 5000 spectrophotometer, working in the range of wavenumbers $50000-4000 \mathrm{~cm}^{-1}$. UV-Vis spectra are reported in the Kubelka-Munk function:

$\left[f\left(R_{\infty}\right)=\left(1-R_{\infty}\right)^{2} / 2 R_{\infty}\right.$

where $\mathrm{R}_{\infty}=$ reflectance of an "infinitely thick" layer of the sample. All the spectra were acquired in air and the samples were examined without any preliminary activation.

FTIR measurements were performed on a Perkin Elmer 2000 spectrometer equipped with a cryogenic MCT detector. The FTIR spectra of adsorbed molecules were performed on the samples in self-supporting pellets introduced in a cell allowing thermal treatments in controlled atmospheres and spectrum scanning at controlled temperatures (from $-180^{\circ} \mathrm{C}$ to $25^{\circ} \mathrm{C}$ ). From each spectrum, the spectrum of the sample before the inlet of the molecule was subtracted. The spectra were normalised respect to the weight of the pellets. Before $\mathrm{CO}$ adsorption at low temperature, the catalysts were submitted to outgassing at r.t., at $50{ }^{\circ} \mathrm{C}$ and at $120{ }^{\circ} \mathrm{C}$. Each outgassing was performed for 30 minutes. Moreover, $\mathrm{CO}$ adsorption experiments on preadsorbed methanol, furfural as well as methanol-furfural and methanol-furfural oxygen mixtures were carried out on the catalysts previously outgassed at $120^{\circ} \mathrm{C}$.

Powder X-Ray Diffraction (PXRD) patterns were collected with a PW3050/60 X'Pert PRO MPD diffractometer from PANalytical working in Bragg-Brentano geometry, using as a source the high-powered ceramic tube PW3373/10 LFF with a Cu anode (using $\mathrm{Cu} \mathrm{K} \mathrm{K}_{\alpha 1}$ radiation $\lambda=1.5406 \AA ̊$ ) equipped with a Ni filter to attenuate $K_{\beta}$. Scattered photons were collected by a real time multiple strip (RTMS) X'celerator detector. Data were collected in the $10^{\circ} \leq 2 \vartheta \leq 100^{\circ}$ angular range, with $0.02^{\circ} 2 \vartheta$ steps. The powdered samples were examined in their as-received form and posed in a spinning sample holder in order to minimize preferred orientations of crystallites.

\section{2-FA oxidative esterification to Me-2-F}

2-FA oxidative esterification was carried out at $120^{\circ} \mathrm{C}$ in the presence of with oxygen and methanol in a mechanical stirred autoclave fitted with an external jacket. No base was added as co-catalyst. Typically, 100 mg catalyst, 2-FA (Sigma Aldrich, >99\%; $300 \mu \mathrm{L}$ ) and n-octane (Sigma Aldrich, >99\%; 150 $\mu \mathrm{L}$, used as internal standard), were added to $150 \mathrm{~mL}$ methanol, that acts as reactant and solvent. The reactor was charged with 6 bar $\mathrm{O}_{2}$ and stirred at $1000 \mathrm{rpm}$. To monitor the reaction, gas-chromatographic analysis was performed on the converted mixture (capillary column HP-5, FID detector). Bare ceria displays no catalytic activity under these reaction conditions ${ }^{[13]}$.

Microwave (MW) -assisted tests on 2-FA oxidative esterification to Me-2-F were carried out in a SynthWAVE (MLS GmbH, Milestone Srl) reactor equipped with a closed MW-cavity. The reaction was 
performed in the presence of $\mathrm{CH}_{3} \mathrm{OH}$ as the solvent. In a typical experiment, the AuCePVA catalyst (20 mg) was added to $60 \mu \mathrm{L}(222.72 \mathrm{mmol})$ of 2-FA with methanol in excess $(30 \mathrm{~mL})$ and heated in $\mathrm{O}_{2}$ atmosphere at different pressures under MW and magnetical stirring to the required temperature for the required time. $\mathrm{N}_{2}$ was added to increase the counter-pressure and avoid solvent volatilization. Catalytic tests were also performed on AuCeDP and on bare ceria. After filtration, the mixture was analysed by GC-MS. GC-MS analyses were performed on a GC Agilent 6890 (Agilent Technologies - USA), fitted with a Agilent Network 5973 mass detector, using an HP-5MS 5\% Phenyl Methyl Siloxane column (30 m long capillary column, an i.d. of $0.25 \mathrm{~mm}$ and a film thickness of $0.25 \mu \mathrm{m}$ ).

\section{Acknowledgements}

S. T., M. M. and G. C. gratefully acknowledge the Università degli Studi di Torino (Progetto Ricerca Locale 2018).

[1] R. Mariscal, P. Maireles-Torres, M. Ojeda, I. Sádaba, M. López Granados, Energy Environ. Sci. 2016, 9, 1144-1189.

[2] X. Li, P. Jia, T. Wang, ACS Catal. 2016, 6, 7621-7640.

[3] M. J. Climent, A. Corma, S. Iborra, Green Chem. 2014, 16, 516.

[4] K. Huang, Z. J. Brentzel, K. J. Barnett, J. A. Dumesic, G. W. Huber, C. T. Maravelias, ACS Sustain. Chem. Eng. 2017, 5, 4699-4706.

[5] S. Tang, J. Yuan, C. Liu, A. Lei, Dalt. Trans. 2014, 43, 13460-13470.

[6] F. Luo, C. Pan, J. Cheng, Synlett 2012, 23, 357-366.

[7] M. Signoretto, F. Menegazzo, L. Contessotto, F. Pinna, M. Manzoli, F. Boccuzzi, Appl. Catal. B Environ. 2013, 129, DOI 10.1016/j.apcatb.2012.09.035.

[8] F. Menegazzo, T. Fantinel, M. Signoretto, F. Pinna, M. Manzoli, J. Catal. 2014, 319, DOI 10.1016/j.jcat.2014.07.017.

[9] C. Ampelli, G. Centi, C. Genovese, G. Papanikolaou, R. Pizzi, S. Perathoner, R.-J. van Putten, K. J. P. Schouten, A. C. Gluhoi, J. C. van der Waal, Top. Catal. 2016, 59, 1659-1667.

[10] M. Manzoli, F. Menegazzo, M. Signoretto, D. Marchese, M. Manzoli, F. Menegazzo, M. Signoretto, D. Marchese, Catalysts 2016, 6, 107.

[11] O. Casanova, S. Iborra, A. Corma, J. Catal. 2009, 265, 109-116.

[12] F. Pinna, A. Olivo, V. Trevisan, F. Menegazzo, M. Signoretto, M. Manzoli, F. Boccuzzi, Catal. Today 2013, 203, DOI 10.1016/j.cattod.2012.01.033.

[13] M. Manzoli, F. Menegazzo, M. Signoretto, G. Cruciani, F. Pinna, J. Catal. 2015, 330, 465-473. 
[14] E. Smolentseva, V. V. Costa, R. F. Cotta, O. Simakova, S. Beloshapkin, E. V. Gusevskaya, A. Simakov, ChemCatChem 2015, 7, 1011-1017.

[15] F. Menegazzo, M. Signoretto, T. Fantinel, M. Manzoli, J. Chem. Technol. Biotechnol. 2017, 92, DOI 10.1002/jctb.5240.

[16] F. Menegazzo, M. Manzoli, A. Di Michele, E. Ghedini, M. Signoretto, Top. Catal. 2018, DOI 10.1007/s11244-018-1003-5.

[17] E. Kowalska, O. O. P. Mahaney, R. Abe, B. Ohtani, Phys. Chem. Chem. Phys. 2010, 12, 2344.

[18] X. Zhang, Y. L. Chen, R.-S. Liu, D. P. Tsai, Reports Prog. Phys. 2013, 76, 046401.

[19] J. Tiggesbäumker, L. Köller, H. O. Lutz, K. H. Meiwes-Broer, Chem. Phys. Lett. 1992, 190, 42-47.

[20] A. Liebsch, Phys. Rev. B 1993, 48, 11317-11328.

[21] A. Moores, F. Goettmann, New J. Chem. 2006, 30, 1121.

[22] L. Prati, A. Villa, Acc. Chem. Res. 2014, 47, 855-863.

[23] F. Menegazzo, M. Signoretto, T. Fantinel, M. Manzoli, J. Chem. Technol. Biotechnol. 2017, 92, 21962205.

[24] A. Villa, D. Wang, D. S. Su, L. Prati, ChemCatChem 2009, 1, 510-514.

[25] A. Quintanilla, V. C. L. Butselaar-Orthlieb, C. Kwakernaak, W. G. Sloof, M. T. Kreutzer, F. Kapteijn, J. Catal. 2010, 271, 104-114.

[26] F. Boccuzzi, A. Chiorino, M. Manzoli, P. Lu, T. Akita, S. Ichikawa, M. Haruta, J. Catal. 2001, 202, DOI 10.1006/jcat.2001.3290.

[27] A. Badri, C. Binet, J.-C. Lavalley, J. Chem. Soc. Faraday Trans. 1997, 93, 1159-1168.

[28] T. Tabakova, F. Boccuzzi, M. Manzoli, D. Andreeva, Appl. Catal. A Gen. 2003, 252, DOI 10.1016/S0926-860X(03)00493-9.

[29] L. Prati, G. Martra, Gold Bull. 1999, 32, 96-101.

[30] T. Tabakova, F. Boccuzzi, M. Manzoli, D. Andreeva, Appl. Catal. A Gen. 2003, 252, 385-397.

[31] D. Cravotto, G., Carnaroglio, Ed. , "Microwave Chemistry" De Guyter Textbook, De Gruyter, 2017.

[32] Y. Tsukahara, A. Higashi, T. Yamauchi, T. Nakamura, M. Yasuda, A. Baba, Y. Wada, J. Phys. Chem. C 2010, 114, 8965-8970.

[33] C. Ampelli, K. Barbera, G. Centi, C. Genovese, G. Papanikolaou, S. Perathoner, K. J. Schouten, J. K. van der Waal, Catal. Today 2016, 278, 56-65.

[34] F. Menegazzo, M. Signoretto, F. Pinna, M. Manzoli, V. Aina, G. Cerrato, F. Boccuzzi, J. Catal. 2014, 309, DOI 10.1016/j.jcat.2013.10.005.

[35] M. I. Zaki, G. A. M. Hussein, S. A. A. Mansour, H. M. Ismail, G. A. H. Mekhemer, Colloids Surfaces A Physicochem. Eng. Asp. 1997, 127, 47-56.

[36] H. Kargar, H. Ghazavi, M. Darroudi, Ceram. Int. 2015, 41, 4123-4128.

[37] M. . Centeno, M. Paulis, M. Montes, J. . Odriozola, Appl. Catal. A Gen. 2002, 234, 65-78. 
[38] A. Bensalem, F. Bozon-Verduraz, M. Delamar, G. Bugli, Appl. Catal. A, Gen. 1995, 121, 81-93.

[39] C. Schilling, C. Hess, J. Phys. Chem. C 2018, 122, 2909-2917.

[40] F. Vindigni, M. Manzoli, A. Damin, T. Tabakova, A. Zecchina, Chem. - A Eur. J. 2011, 17, 4356-4361.

[41] J. Bansmann, A. M. Abdel-Mageed, S. Chen, C. Fauth, T. Häring, G. Kučerová, Y. Wang, R. J. Behm, Catalysts 2019, 9, 785.

[42] Y. Li, L. Wang, R. Yan, J. Han, S. Zhang, Catal. Sci. Technol. 2015, 5, 3682-3692.

[43] A. Trovarelli, Catalysis by Ceria and Related Materials, Imperial College Press, London, 2002.

[44] M. Melchionna, P. Fornasiero, Mater. Today 2014, 17, 349-357. 
Entry for the Table of Contents

FULL PAPER

\begin{tabular}{|c|c|c|}
\hline $\begin{array}{l}\text { achieved at } 120{ }^{\circ} \mathrm{C} \text { over } \\
\mathrm{Au}^{\mathrm{C}} \mathrm{CO}_{2} \text { obtained by } \\
\text { depositing gold colloids. The } \\
\text { polyvinyl alcohol protective } \\
\text { agent acted as gold stabilizer } \\
\text { and as mediator with the } \\
\text { reactants, leaving both Au and } \\
\text { ceria sites available for } \\
\text { catalysis also under MW } \\
\text { irradiation. The produced Ce }{ }^{3+} \\
\text { sites catalysed acetal } \\
\text { formation lowering selectivity, } \\
\text { according to a different } \\
\text { mechanism. }\end{array}$ & 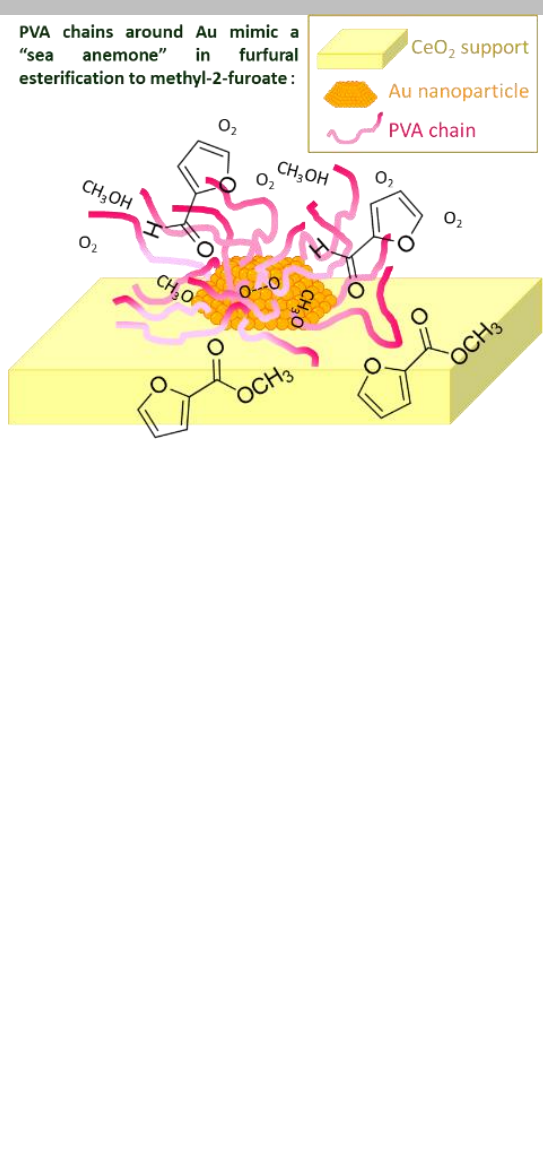 & $\begin{array}{l}\text { G. Grillo, F. Menegazzo, S. } \\
\text { Tabasso, M. Signoretto, M. } \\
\text { Manzoli*, G. Cravotto } \\
\text { * } \\
\text { Page No. - Page No. } \\
\text { New insights on the dynamic } \\
\text { role of the protecting agent on } \\
\text { the reactivity of supported gold } \\
\text { nanoparticles }\end{array}$ \\
\hline
\end{tabular}


Supporting information

New insights on the dynamic role of the protecting agent on the reactivity of supported gold nanoparticles

Giorgio Grillo, ${ }^{a}$ Federica Menegazzo, ${ }^{\mathrm{b}}$ Silvia Tabasso, ${ }^{\mathrm{c}}$ Michela Signoretto, ${ }^{\mathrm{b}}$ Maela Manzoli, ${ }^{\mathrm{a} a}$ and Giancarlo Cravotto $^{\mathrm{a}}$

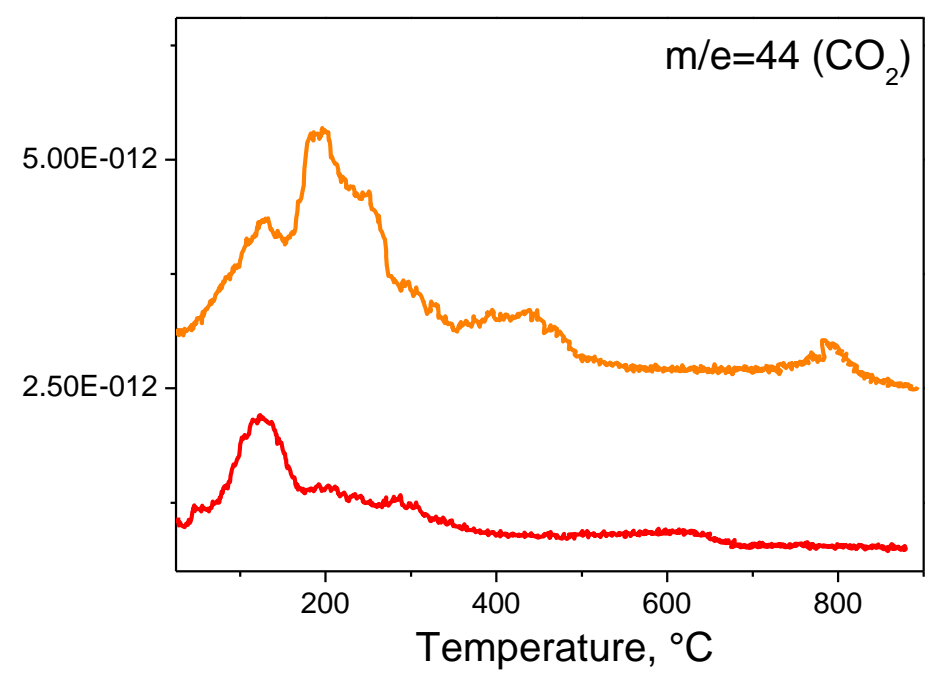

Figure SI-1. TPO curves of as synthesised AuCePVA (orange line) and AuCeDP (red line). 

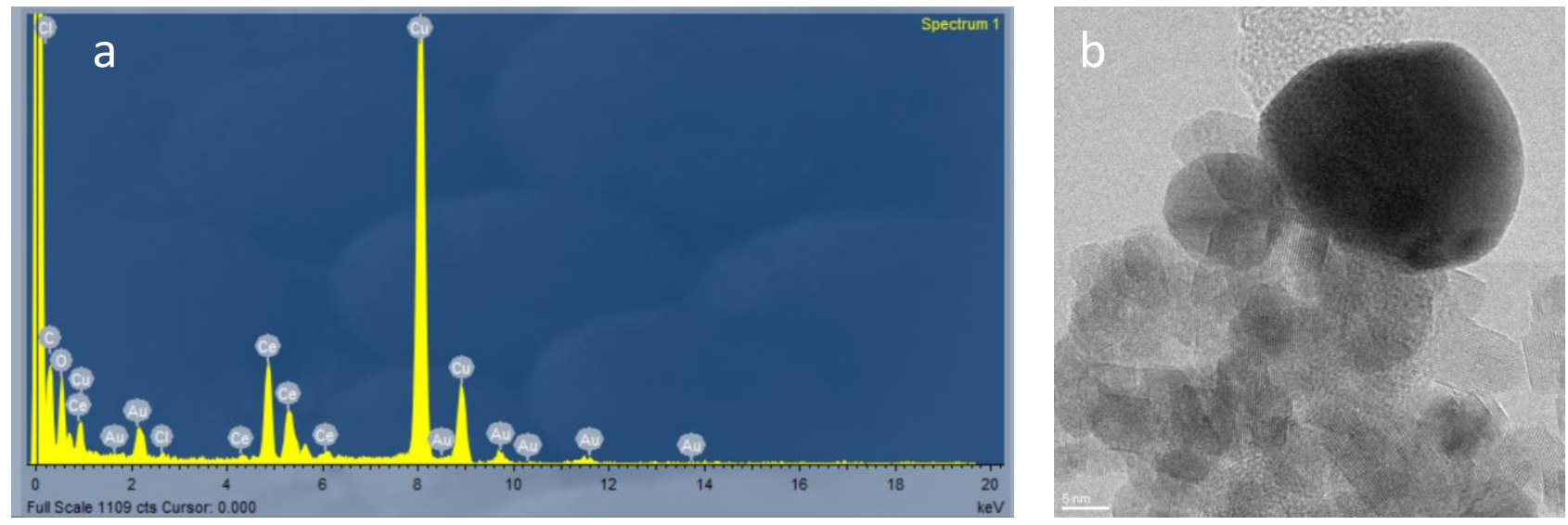

Figure SI-2. EDS spectrum collected on the Au nanoparticle shown in Figure 1b, HR-TEM image of a big Au particle observed on the AuCeDP catalyst. Instrumental magnification: $400000 \times$.

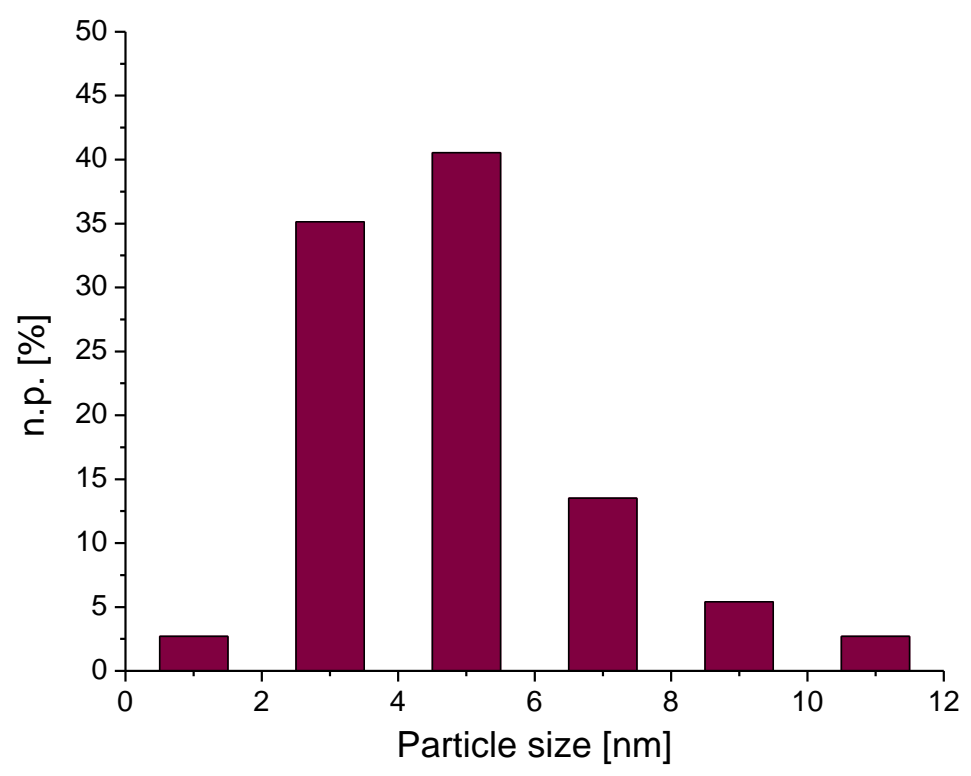

Figure SI-3. Au particle size distribution of the AuCePVA catalyst after 2-FA oxidative esterification to Me-2$F$, n.p. [\%] $=$ number of counted particles of diameter $d_{i}$. 

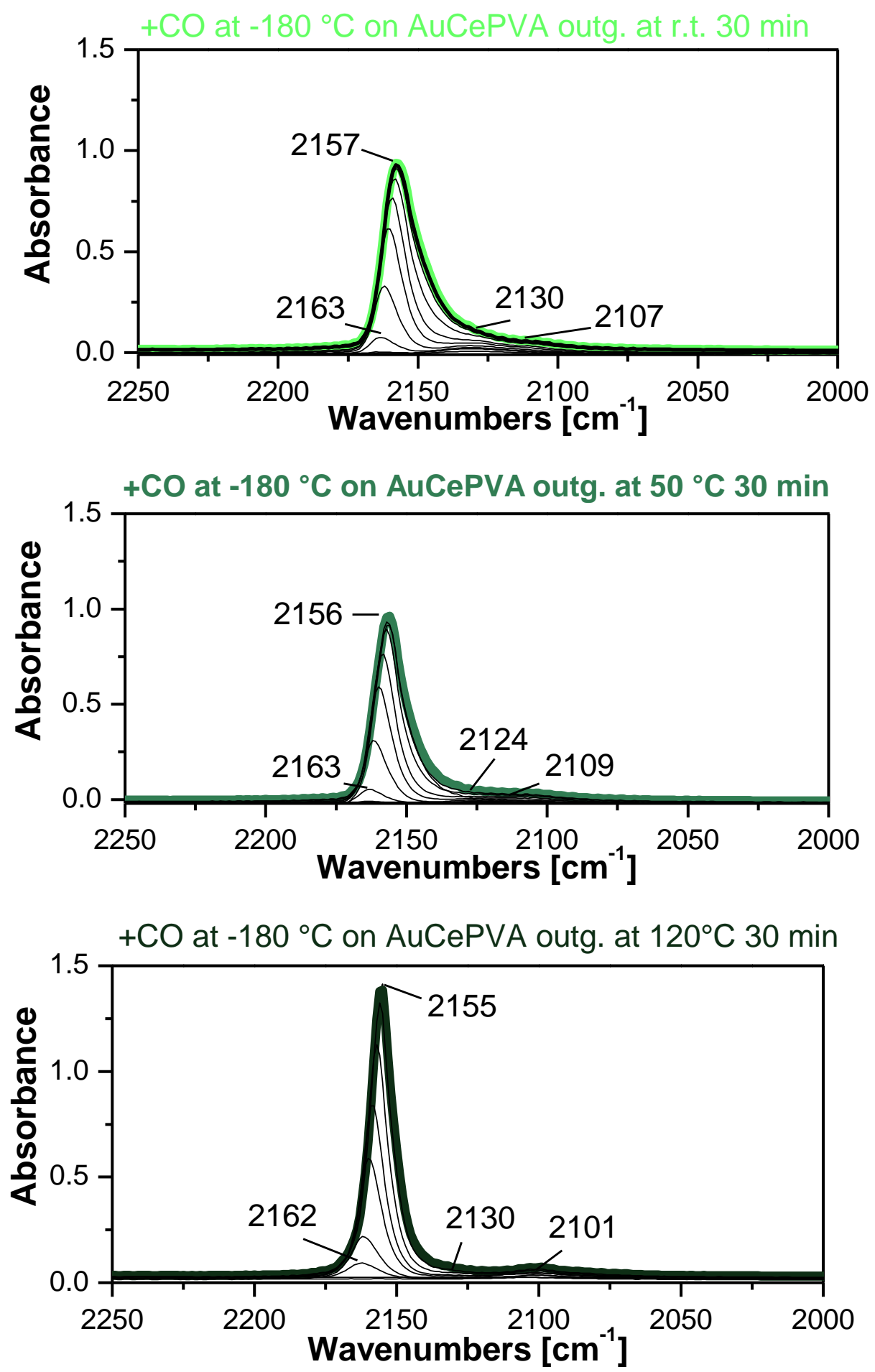

Figure SI-4. FTIR difference spectra collected upon the inlet of $7.5 \mathrm{mbar} \mathrm{CO}$ at $-180{ }^{\circ} \mathrm{C}$ on AuCePVA outgassed at room temperature (light green line), $50{ }^{\circ} \mathrm{C}$ (green line) and $120{ }^{\circ} \mathrm{C}$ (dark green line) and at reducing $\mathrm{CO}$ pressures (light black lines). 


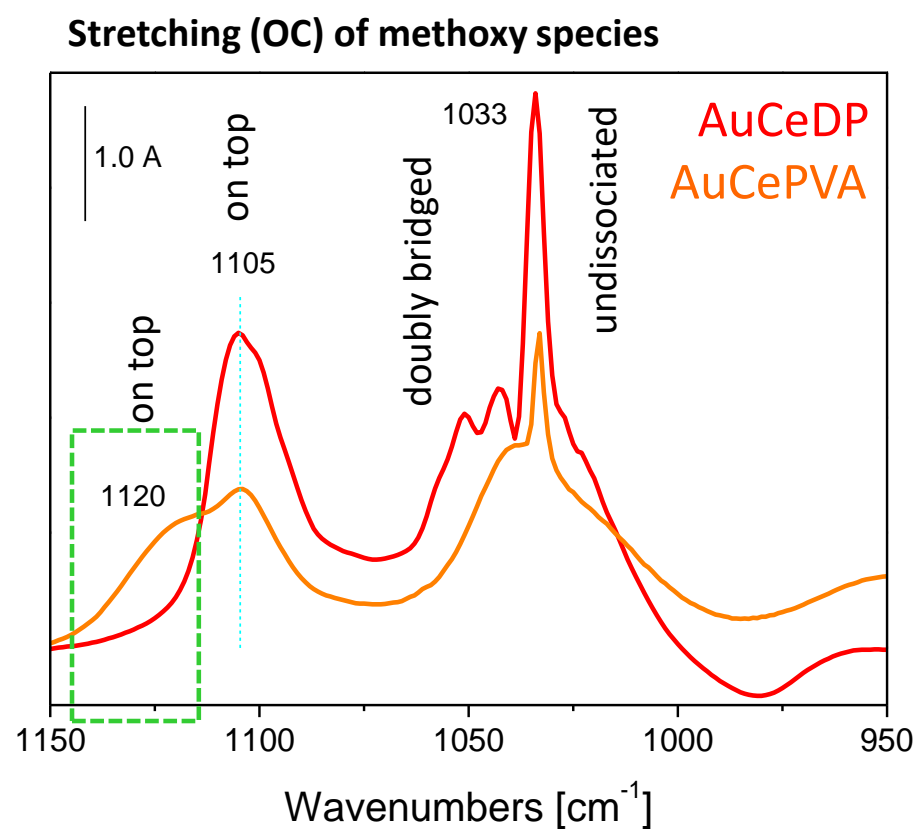

Figure SI-5. FTIR difference spectra collected upon the inlet of $10 \mathrm{mbar}$ methanol at room temperature on AuCePVA (orange curve) and AuCeDP (red curve).

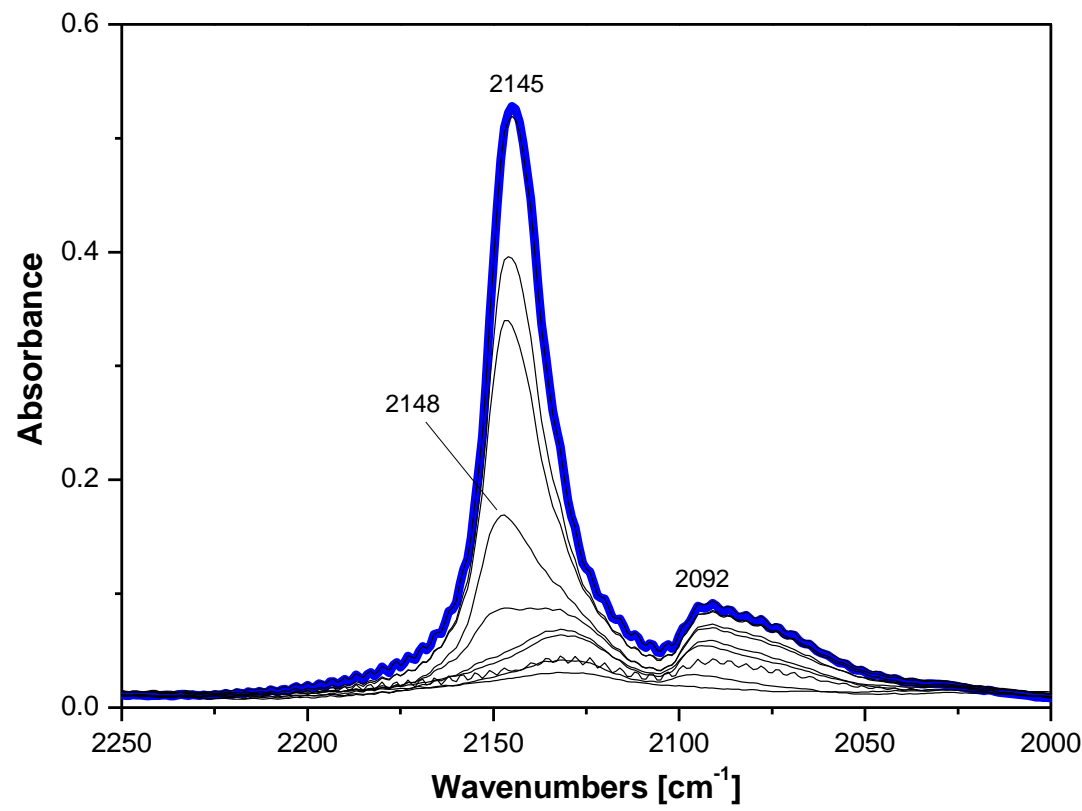

Figure SI-6. FTIR difference spectra collected upon the inlet of $7.5 \mathrm{mbar} \mathrm{CO}$ at $-180^{\circ} \mathrm{C}$ on AuCeDP previously heated in $10 \mathrm{mbar}$ methanol at $120^{\circ} \mathrm{C}$ for 30 minutes and outgassed at room temperature (blue line) and at reducing CO pressures (light black lines). 


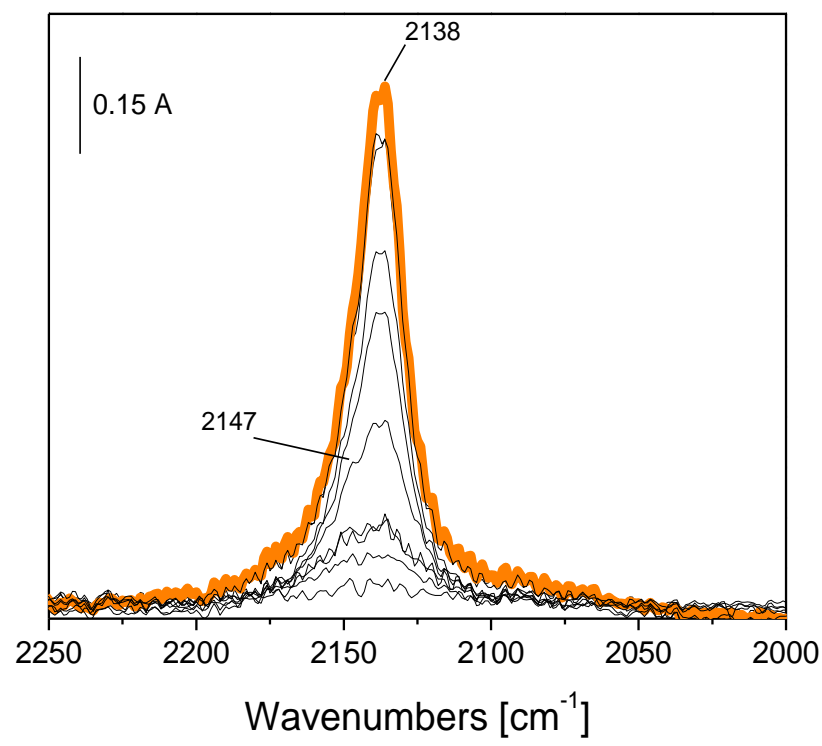

Figure SI-7. FTIR difference spectra collected upon the inlet of $7.5 \mathrm{mbar}$ CO at $-180{ }^{\circ} \mathrm{C}$ on AuCePVA previously heated in $10 \mathrm{mbar}$ furfural at $120^{\circ} \mathrm{C}$ for 30 minutes and outgassed at room temperature (orange line) and at reducing CO pressures (light black lines).

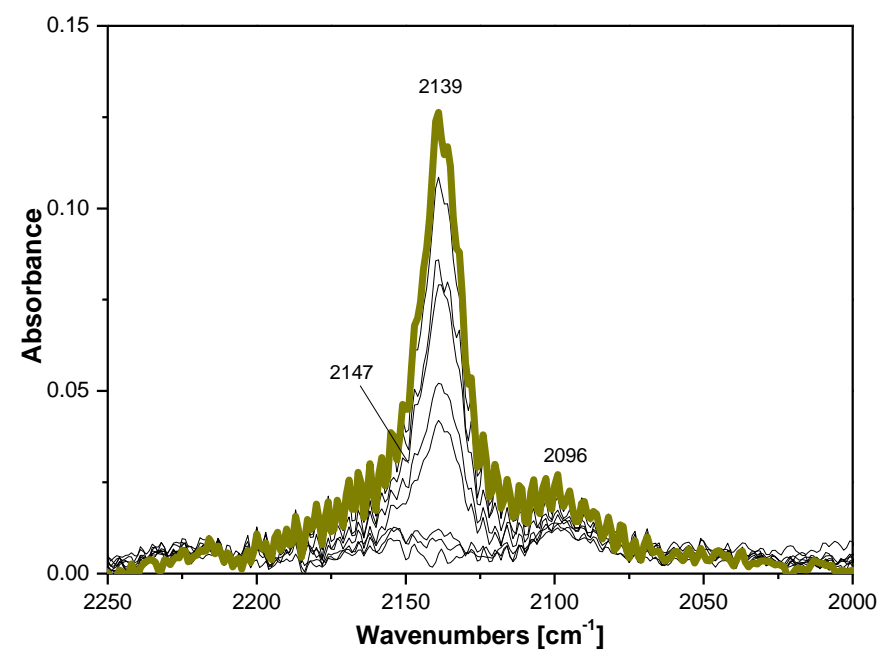

Figure SI-8. FTIR difference spectra collected upon the inlet of $7.5 \mathrm{mbar} \mathrm{CO}$ at $-180{ }^{\circ} \mathrm{C}$ on AuCePVA previously heated in $10 \mathrm{mbar}$ methanol at $120^{\circ} \mathrm{C}$ for 30 minutes, outgassed at room temperature and then heated in 10 mbar furfural at $120^{\circ} \mathrm{C}$ for 30 minutes and outgassed at room temperature (dark yellow line) and at reducing CO pressures (light black lines). 




Figure SI-9. (a) FTIR difference spectra of AuCePVA after the inlet of a methanol:furfural:oxygen (5 mbar:10 mbar:30 mbar) at room temperature (black line) and at $120^{\circ} \mathrm{C}$ for 30 minutes (red line). (b) FTIR difference spectra collected upon the inlet of $7.5 \mathrm{mbar} \mathrm{CO}$ at $-180{ }^{\circ} \mathrm{C}$ on AuCePVA previously heated of a methanol:furfural:oxygen ( 5 mbar:10 mbar:30 mbar) at $120{ }^{\circ} \mathrm{C}$ for 30 minutes and outgassed at room temperature (wine line) and at reducing $\mathrm{CO}$ pressures (black lines).

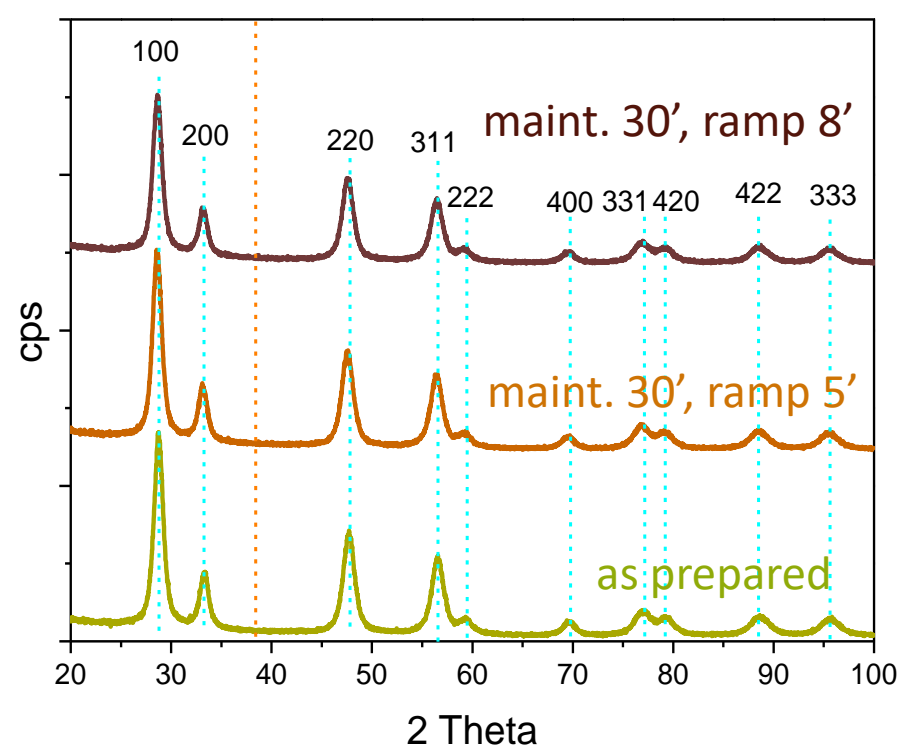

Figure SI-10. XRD patterns of as prepared bare ceria and after 30 minutes reaction time under MW irradiation at $120^{\circ} \mathrm{C}$, at different heating ramps ( 5 minutes, avg. $875 \mathrm{~W}$ and 8 minutes, avg. $522 \mathrm{~W}$ ). 